Prepared in cooperation with the U.S. Fish and Wildlife Service

\title{
Mapping Phragmites australis Live Fractional Cover in the Lower Mississippi River Delta, Louisiana
}

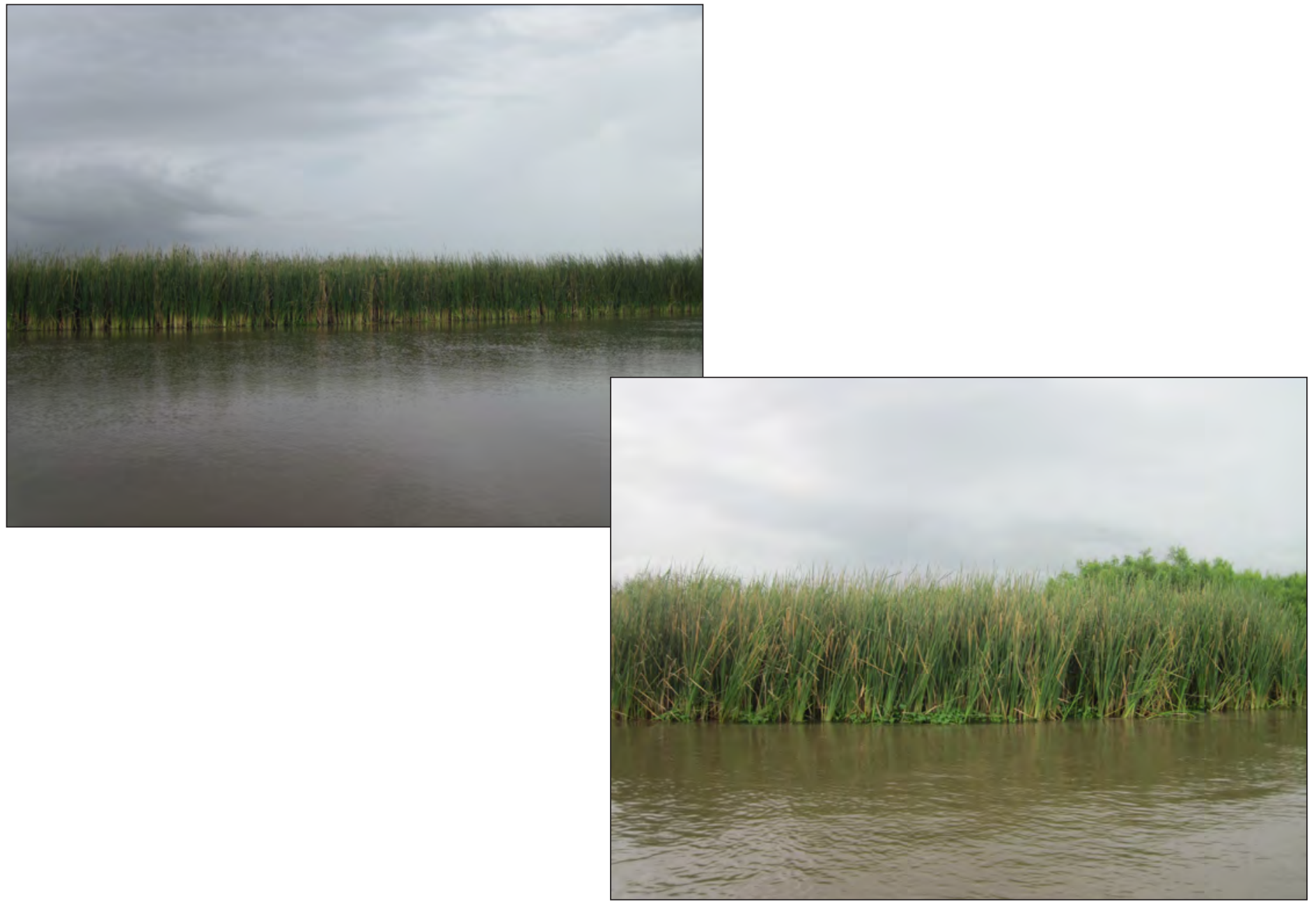

Open-File Report 2020-1131

Version 1.1, January 2021 
Cover. Photographs showing roseau cane (Phragmites australis) along the Main Pass canal, Louisiana. Photographs by Elijah W. Ramsey III, U.S. Geological Survey. 


\section{Mapping Phragmites australis Live Fractional Cover in the Lower Mississippi River Delta, Louisiana}

By Amina Rangoonwala, Rebecca J. Howard, and Elijah W. Ramsey III

Prepared in cooperation with the U.S. Fish and Wildlife Service

Open-File Report 2020-1131

Version 1.1, January 2021

U.S. Department of the Interior

U.S. Geological Survey 


\section{U.S. Geological Survey, Reston, Virginia \\ First release: 2020 \\ Revised: January 2021 (ver. 1.1)}

For more information on the USGS - the Federal source for science about the Earth, its natural and living resources, natural hazards, and the environment-visit https://www.usgs.gov or call 1-888-ASK-USGS.

For an overview of USGS information products, including maps, imagery, and publications, visit https://store.usgs.gov/.

Any use of trade, firm, or product names is for descriptive purposes only and does not imply endorsement by the U.S. Government.

Although this information product, for the most part, is in the public domain, it also may contain copyrighted materials as noted in the text. Permission to reproduce copyrighted items must be secured from the copyright owner.

Suggested citation:

Rangoonwala, A., Howard, R.J., and Ramsey, E.W., III, 2020, Mapping Phragmites australis live fractional cover in the lower Mississippi River Delta, Louisiana (ver. 1.1, January 2021): U.S. Geological Survey Open-File Report 2020-1131, 24 p., https://doi.org/10.3133/ofr20201131.

Associated data for this publication:

Rangoonwala, A., and Ramsey, E.W., III, 2020, Phragmites australis live fractional cover yearly map from 2009 to 2019 of the lower Mississippi River Delta using Landsat and Sentinel-2 satellite data: U.S. Geological Survey data release, https://doi.org/10.5066/P9ASPB4E.

ISSN 2331-1258 (online) 


\section{Acknowledgments}

We thank William G. Thomas II (Invasive Species Coordinator/Strike Team Leader, U.S. Fish and Wildlife Service Region 4) for supporting our proposed work and Sue Wilder, previously with the U.S. Fish and Wildlife Service, for help in preparing the study proposal. Neil Lalonde (Project Leader at the U.S. Fish and Wildlife Service, Southeast Louisiana National Wildlife Refuges [NWR] Complex) and Barret K. Fortier (Acting Refuge Manager for the Delta and Breton NWRs) are appreciated for allowing access to the Delta NWR and for providing transport to the field sites throughout the NWR. We thank Max Latham, U.S. Fish and Wildlife Service, for helping us obtain the field data we needed for this study. We thank Brian Snyder, Professor at the Department of Environmental Sciences at Louisiana State University, and Stephen Hartley, U.S. Geological Survey Wetlands and Aquatic Research Center, for providing thorough and effective reviews of this report. 



\section{Contents}

Acknowledgments ……...................................................................................................................

Abstract

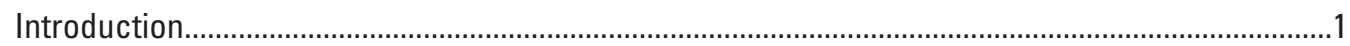

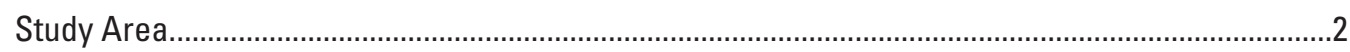

Methods

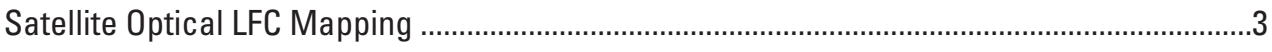

Optical Image Selection for Field VI Calibration..............................................................

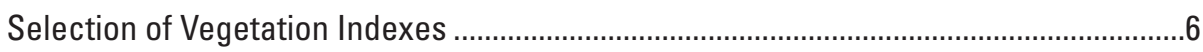

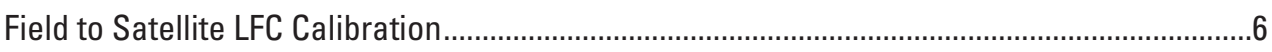

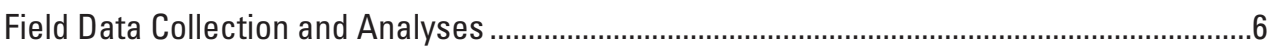

Field Simulation of Satellite VI Data .................................................................................

Vegetation Live Fractional Cover Classification ................................................................

Challenges in Relating Field to Satellite Measurements ..................................................

Water Mask Creation and Above-Surface Water Levels .........................................................10

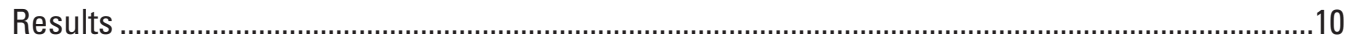

Field Reflectance Spectra .............................................................................................

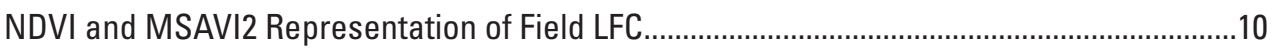

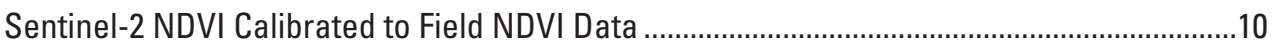

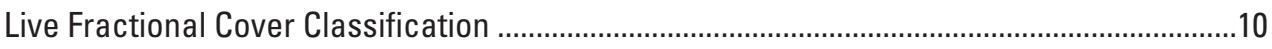

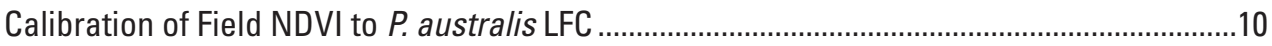

Sentinel-2 LFC Mapping Extended to Landsat ......................................................................11

LFC Status and Change Maps.......................................................................................

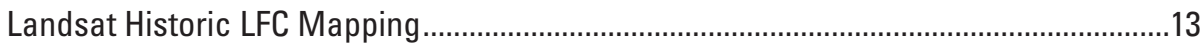

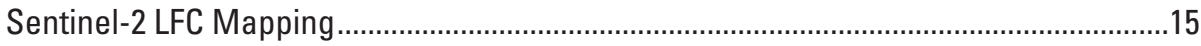

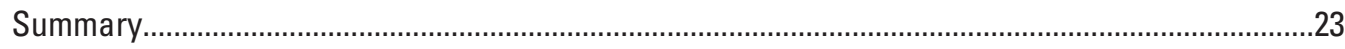

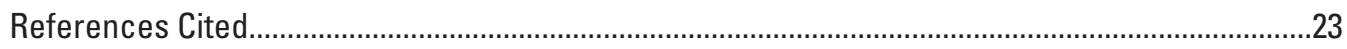

\section{Figures}

1. A Sentinel-2 optical image of the lower Mississippi River Delta study region, Louisiana, August 31, 2019

2. Image showing Phragmites australis within the U.S. Fish and Wildlife Service Delta National Wildlife Refuge in 2016 .......................................................................

3. Photograph showing field collection of reflectance spectra and webcam images .........7

4. Graph showing reflectance spectra calculated from radiometer data collected

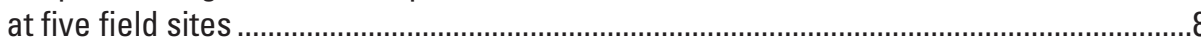

5. Webcam photographs shown on the left and its classification shown on the right. Site S3, a mixed Phragmites marsh site; site S8 and two locations at site S10, pure Phragmites marsh sites; and site S7, a pure elephant-ear site ...

6. Graph showing the correspondence between the normalized difference vegetation index calculated from site-location averaged field reflectance data and from site Sentinel-2 satellite reflectance data.. 
7. Graph showing the best-fit nonlinear regression model between the field normalized difference vegetation index calculated from field reflectance data and webcam live fractional cover classifications.

8. Graphs showing the September 30,2016 , Landsat count frequencies overlain on the September 20, 2016, Sentinel-2 normalized difference vegetation index count frequencies for the Mississippi River Delta, Louisiana, and the Phragmite marshes at the U.S. Fish and Wildlife Service Delta National Wildlife Refuge, Louisiana

9. Maps showing the September 20, 2016, Sentinel-2 normalized difference vegetation index (NDVI) and September 30, 2016, Landsat NDVI, U.S. Fish and Wildlife Service Delta National Wildlife Refuge, Louisiana

10. Maps showing comparison of 2016 Sentinel-2 and Landsat Live Fractional Cover (LFC) maps centered on the Delta NWR from the September 20, 2016, Sentinel-2 LFC and September 30, 2016, Landsat LFC maps.

11. Map showing Landsat live fractional cover for the lower Mississippi River Delta, Louisiana, May 25, 2010 .15

12. Map showing Landsat live fractional cover for the lower Mississippi River Delta, Louisiana, June 13, 2011. 16

13. Map showing Landsat live fractional cover change for the lower Mississippi River Delta, Louisiana, May 25, 2010, to June 13, 2011

14. Map showing Sentinel-2 Live Fractional Cover for the lower Mississippi River Delta, Louisiana, September 20, 2016.

15. Map showing Sentinel-2 Live Fractional Cover for the lower Mississippi River Delta, Louisiana, October 25, 2017

16. Map showing Sentinel-2 Live Fractional Cover for the lower Mississippi River Delta, Louisiana, October 30, 2018. .20

17. Map showing Sentinel-2 Live Fractional Cover change for the lower Mississippi River Delta, Louisiana, October 25, 2017, to October 30, 2018.

18. Map showing Sentinel-2 Live Fractional Cover (LFC) color composite displaying the 2016 LFC as red, 2017 LFC as green, and 2018 LFC as blue for the lower Mississippi River Delta, Louisiana..

\section{Tables}

1. Above-marsh surface-water levels at Louisiana Coastwide Reference Monitoring System sites at image collection times for the Delta National Wildlife Refuge, Louisiana.

2. Location information for sites used for mapping Phragmites australis, also commonly called roseau cane, in the Delta National Wildlife Refuge, Louisiana.

3. Landsat Live Fractional Cover change maps of the lower Mississippi River Delta ........14

4. Sentinel-2 Live Fractional Cover change maps of the lower Mississippi River Delta ....18 


\section{Conversion Factors}

International System of Units to U.S. customary units

\begin{tabular}{lll}
\hline \multicolumn{1}{c}{ Multiply } & By & \multicolumn{1}{c}{ To obtain } \\
\hline meter $(\mathrm{m})$ & Length & \\
kilometer $(\mathrm{km})$ & 3.281 & foot $(\mathrm{ft})$ \\
kilometer $(\mathrm{km})$ & 0.6214 & mile (mi) \\
meter $(\mathrm{m})$ & 0.5400 & mile, nautical $(\mathrm{nmi})$ \\
\hline
\end{tabular}

\section{Abbreviations}

$\begin{array}{ll}\leq & \text { less than or equal to } \\ \text { GSA } & \text { ground surface area } \\ \text { LFC } & \text { live fractional cover } \\ \text { MRD } & \text { Mississippi River Delta } \\ \text { MSAVI2 } & \text { Modified Soil Adjusted Vegetation Index 2 } \\ \text { NDVI } & \text { normalized difference vegetation index } \\ \text { NIR } & \text { near infrared } \\ \text { NWR } & \text { National Wildlife Refuge } \\ \text { RMSE } & \text { root-mean-square error } \\ \text { SAR } & \text { synthetic aperture radar } \\ \text { USFWS } & \text { U.S. Fish and Wildlife Service } \\ \text { USGS } & \text { U.S. Geological Survey } \\ \text { VI } & \text { vegetation index }\end{array}$





\title{
Mapping Phragmites australis Live Fractional Cover in the Lower Mississippi River Delta, Louisiana
}

\author{
By Amina Rangoonwala, ${ }^{1}$ Rebecca J. Howard, ${ }^{2}$ and Elijah W. Ramsey III ${ }^{3}$
}

\section{Abstract}

In response to a co-occurring non-native scale infestation and Phragmites australis dieback in southeast Louisiana, normalized difference vegetation index (NDVI) satellite mapping was implemented to track $P$. australis condition in the lower Mississippi River Delta. While the NDVI mapping successfully documented relative condition changes, identification of cause required a quantitative-biophysical metric directly related to $P$. australis marsh live vegetation proportion. During this study, a satellite mapping tool that quantified $P$. australis live fraction cover (LFC) magnitude was designed and implemented. The key to development of the quantitative LFC mapping was the field to satellite calibration design. The calibration of $P$. australis marsh LFC to optical satellite image data combined field and near-in-time satellite data collections in the fall of 2018 and summer of 2019. Basing the field-NDVI to field-LFC calibrations and the satellite-NDVI to field-NDVI calibrations on combined pre-senescence and peak-growth period data offers nearly year-round LFC mapping. The utility of the developed $P$. australis marsh LFC mapping tool was demonstrated by the creation of a yearly suite of Mississippi River Delta LFC status and change maps extending from 2009 to 2019. P. australis marsh LFC mapping relies on Sentinel-2 for current to future mapping and relies on Landsat for historical mapping.

\section{Introduction}

Although invasive, Phragmites australis is the dominant plant species in marshes of the lower Mississippi River Delta (Hauber and others, 2011; Baurick, 2017). The recent widespread dieback of $P$. australis in coastal marshes of southeastern Louisiana was first noted in the fall of 2016 (Knight and others, 2018). The occurrence of a nonnative scale insect (Nipponaclerda biwakoensis) that infests P. australis stands

\footnotetext{
${ }^{1}$ Contractor to the U.S. Geological Survey.
}

2U.S. Geological Survey Emeritus.

${ }^{3}$ U.S. Geological Survey. and the effects of abiotic stressors (for example, excessive flooding) have been implicated as causal mechanisms in this dieback (Knight and others, 2018; Schneider, 2019).

Because native plant species have not replaced dead $P$. australis stands in the Mississippi River Delta, the dieback could negatively affect the Mississippi River Delta by reducing protection against erosion. The height and extensive root system of $P$. australis absorb wave impacts, thwarting erosion and promoting land building that helps stabilize coastal wetlands. The loss of $P$. australis is likely to spur erosion, worsening the already alarming rate of land loss (Baurick, 2017) and threatening the ecological and economic functions of the Mississippi River Delta. P. australis loss also undermines the deltaic wetland support of large populations of ducks, wading birds, fish, and shellfish and the viability of Federal and State wildlife refuges that harbor significant populations of wintering waterfowl. Also, increased erosion could clog shipping channels, posing a threat to navigation. Erosion could expose oil and gas infrastructure, possibly leading to damages to that infrastructure and contamination of already degraded coastal resources.

To help land managers identify the causes of the $P$. australis dieback, the U.S. Geological Survey (USGS) initiated a project to use satellite mapping to document loss as well as to track $P$. australis conditions (Ramsey and Rangoonwala, 2017). That study applied the normalized difference vegetation index (NDVI) calculated from Sentinel-2 and Landsat red (about 600 to 700 nanometers [nm]) and near-infrared (NIR) (about 700 to $1,100 \mathrm{~nm}$ ) optical data to track yearly changes in live vegetation from 2014 to 2017 . NDVI is a unitless ratio indicating the relative amount of green vegetation per ground area ranging from about 0 to 1 or when scaled to 100 from 0 to 100 . Results of the NDVI mapping indicated that $P$. australis marsh diebacks also occurred earlier than the $P$. australis dieback and associated scale infestation in 2016 (Knight and others, 2018). Although NDVI is widely used as a relative indicator of live biomass, the form and significance of the NDVI relation to live biomass vary (Ramsey and others, 2015). To provide a quantifiable measure of $P$. australis marsh status and change, a follow-up study was initiated by the USGS to calibrate NDVI, or a similar vegetation index (VI), to a quantitative metric of percent live vegetation per ground area, referred to as the vegetation live fractional cover (LFC). 
A strategy was needed to translate VI relative status and change to $P$. australis LFC status and change in order to provide key information to managers of the wildlife refuges (Katarzyna and others, 2015) and advance ecological interpretation of change. In regional studies, LFC is the status indicator (Saltz and others, 1999; Liu and others, 2007; Röder and others, 2008). LFC is closely linked to live above-ground biomass and provides a suitable surrogate for remote sensing mapping (Röder and others, 2008).

In addition to quantifying the $P$. australis LFC, the 3-year study described in Ramsey and Rangoonwala (2017) was extended to produce yearly maps showing LFC status and change from 2009 to 2019 in the lower Mississippi River Delta. The yearly 2009 to 2016 snapshots provide a historical sense of $P$. australis marsh LFC status and change over time. The mapping beginning in 2017 shows LFC status and change within the current period of intense field surveys into the $P$. australis marsh.

The objectives of this study were to (1) develop a calibration method for relating a suitable VI to field measures of $P$. australis marsh LFC, (2) transfer the field VI to LFC calibration to the satellite optical VI, (3) prepare yearly LFC maps from 2009 to 2019 including seasonal maps for 2018. In addition, an overarching component of this study was to ensure that the U.S. Fish and Wildlife Service (USFWS) staff could continue the $P$. australis marsh LFC mapping in the future. To that end, the mapping system was built with freely available optical data and a future source of synthetic aperture radar (SAR) data that could be processed with a user-supported free desktop icon-driven processing system.

\section{Study Area}

The study covers the lower Mississippi River Delta in southeastern Louisiana (fig. 1). This subtropical region contains the most diverse assemblage of $P$. australis haplotypes (in other words, lineages) in the world (Lambertini and others, 2012). Although several $P$. australis lineages are native to North America, except for a possible hybrid with P. mauritianus, all Phragmite haplotypes in the Mississippi River Delta are $P$. australis (Lambertini and others, 2012). P. australis is also refereed as roseau cane.

Mapping developments, assessments, and comparisons were carried out in the USFWS Delta National Wildlife Refuge (NWR) in 2018 and 2019 (fig. 2). Those assessments and comparisons greatly benefited from the availability of the P. australis habitat dataset of the Delta NWR from 2016 (Dugas and others, 2018). The Delta NWR contains fresh and brackish marshes (U.S. Department of the Interior, Fish and Wildlife Service, 2008). As reported by Dugas and others (2018) and reproduced in figure 2, the $P$. australis fresh marsh dominates the Delta NWR extent. 


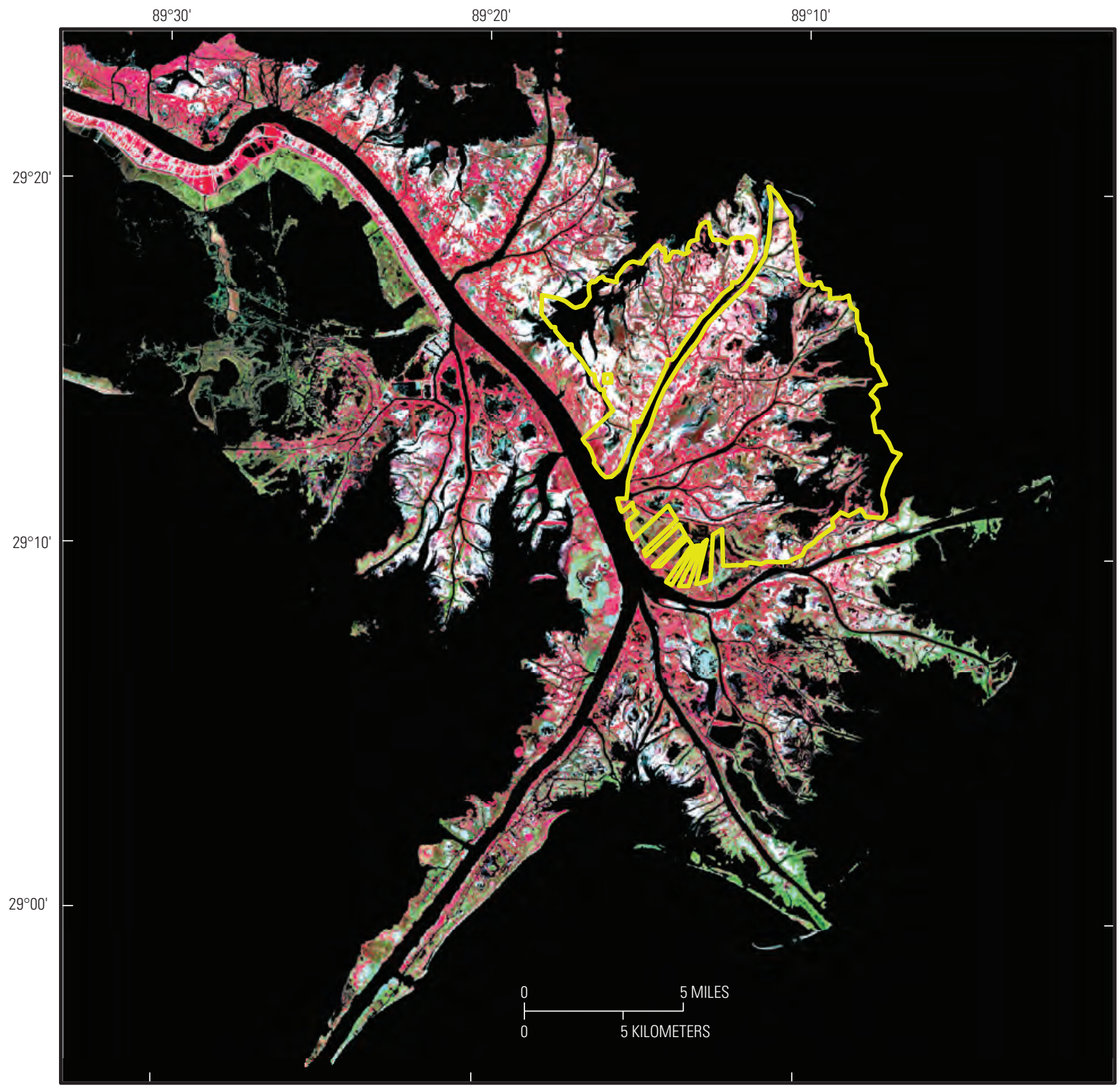

Figure 1. A Sentinel-2 optical image of the lower Mississippi River Delta study region, Louisiana, August 31, 2019. In this near-infrared, red and green band image composite, healthy vegetation tends to appear bright red. The yellow polygon outlines the U.S. Fish and Wildlife Service Delta National Wildlife Refuge.

\section{Methods}

\section{Satellite Optical LFC Mapping}

For $P$. australis marsh LFC mapping, Sentinel-2 was used for current to future mapping, and Landsat was used for historical mapping (Ramsey and Rangoonwala, 2017). A single Sentinel-2 optical image was taken of the entire Mississippi River Delta every 5 days at a 10-meter (m) spatial resolution; that resolution is appropriate for representing the $P$. australis marsh status and change.
The spectral similarity of Sentinel-2 and Landsat provides an adequate mechanism to transfer the created Sentinel-2 mapping technology to Landsat, which has an extensive historical archive. Landsat images also cover the Mississippi River Delta area; however, the Landsat's 16-day repeat frequency and coarser 30-m spatial resolution produces a more generalized map product than does Sentinel-2. Although the Landsat map is generalized, recent Landsat maps can be compared to historical maps for a longer-term assessment of $P$. australis marsh LFC status and changes. 


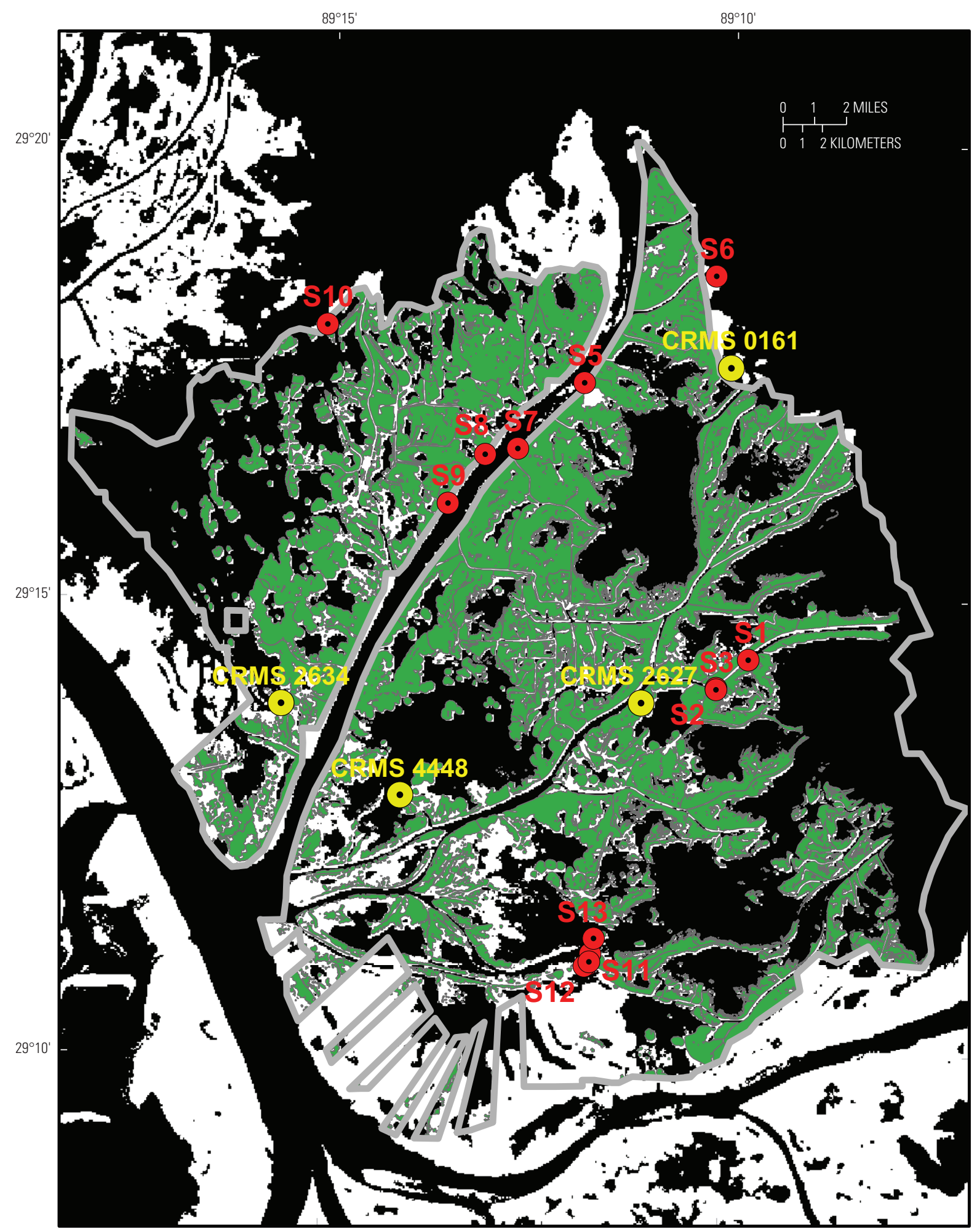

Figure 2. Phragmites australis (green) within the U.S. Fish and Wildlife Service Delta National Wildlife Refuge (gray outline) in 2016. Louisiana Coastwide Reference Monitoring System (CRMS) sites are shown in yellow (table 1), and field sites are shown in red (table 2). 
Atmospheric removal was implemented as an operational component at the onset of processing Sentinel-2 and Landsat image data for this study. The atmospheric removal transforms the Sentinel-2 and Landsat image data to surface reflectance, a direct representation of the aggregate reflectance of the live and dead vegetation and background composition per ground surface area (GSA) at the time of image collection. Free Sentinel-2 image data were downloaded from the European Space Agency Copernicus website (https://scihub.copernicus.eu/dhus/\#/home) (table 1). Sentinel-2 image data were transformed to surface reflectance by applying programs provided by the European Space Agency (http://step.esa.int/main/third-party-plugins-2/sen2cor/). Free Landsat surface reflectance data were downloaded from the USGS Earth Resources Observation and Science Center website (https://earthexplorer.usgs.gov/) (table 1).
The yearly map production was focused on satellite data collected during the full-growth months from June through September. When cloud cover prevented any usable collections during those months, data from April, May, and October were used. In these cases, a part of the calculated yearly change likely included seasonal change. To illustrate the expected magnitude of seasonal change incorporated into the yearly change magnitudes, maps depicting high frequency seasonal change were created. The seasonal change maps included four months in 2018 and four months in 2019. The primary objectives, however, were to detect abnormal change and to use the mapping system developed in this study to track the detected abnormality. Although constant LFC is not expected during the entire 7-month span, that period is when the $P$. australis marsh is expected to be at peak LFC and thus provides the most stable base for detecting abnormal changes.

Table 1. Above-marsh surface-water levels (North American Vertical Datum of 1988) at Louisiana Coastwide Reference Monitoring System (CRMS) sites at image collection times for the Delta National Wildlife Refuge, Louisiana.

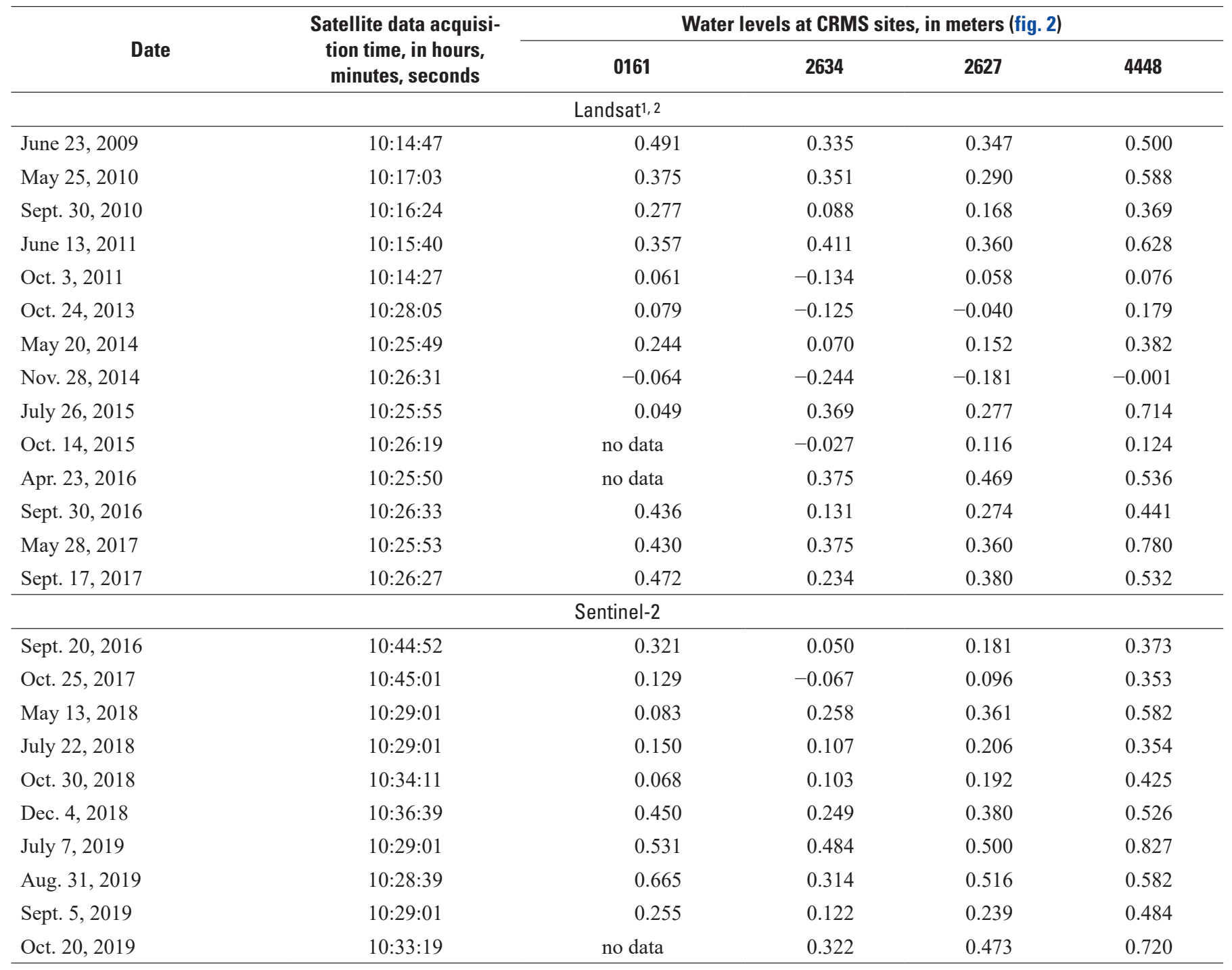

1Usable Landsat data not available in 2012.

${ }^{2}$ Each year coverage required three scenes and two dates. 


\section{Optical Image Selection for Field VI Calibration}

The Sentinel-2 reflectance image collected on October 30, 2018, closest to the November 15-16, 2018, field data collections, was the reference image for late fall field to satellite VI calibration. The Sentinel-2 reflectance image collected on August 31, 2019, closest to the August 20-22 field data collections, was the reference image for summer field to satellite VI calibration. Image data used to calculate the satellite VI were extracted by using the field site central Global Positioning System coordinate and direction of measurement to identify pixels that best represented the sample locations (table 2).

\section{Selection of Vegetation Indexes}

Two VIs were selected to represent LFC; the NDVI and modified soil adjusted VI2 (MSAVI2) (Qi and others, 1994). NDVI is the most commonly used variation of Tucker's (1979) original VI (Guo and others, 2005). In Ramsey and Rangoonwala (2017), NDVI was used primarily to minimize the influence of atmospheric variability remaining in the topof-atmosphere reflectance correction. In this study, correction of the satellite image data to surface reflectance removes the atmosphere's variability in the VI mapping, thus leaving background as a primary noise contributor to VI (Yang and others, 2012). MSAVI2 was added because of its proven capability to minimize background influences in VI mapping and because of its ease of implementation into an operational mapping system (Liu and others, 2007).

\section{Field to Satellite LFC Calibration}

The primary goal of the field activities was to create an equation to calibrate $P$. australis LFC to the satellite VI. The accomplishment of that field to satellite calibration occurred in three steps. First, the field VI data attained with a field radiometer system were calibrated to satellite VI data extracted from the Sentinel-2 reflectance image collected closest in time to the field collections (fig. 3). Second, field VI was calibrated to the live vegetation LFC attained by classifying the webcam photography collected simultaneously with the field radiometer data (fig. 3). Third, the satellite VI adjusted to the field VI was substituted into the field to LFC calibration equation to attain the satellite VI to LFC mapping.

\section{Field Data Collection and Analyses}

Field data were collected during November 15-16, 2018, and August 20-22, 2019, in the USFWS Delta NWR. These dates were chosen to encompass the broadest range of P. australis growth. Sites were located beside waterways that were accessible by boat (fig. 2; table 2). Each site included collections at three locations designated by direction from the site center (for example, site\#-cardinal degree of location). In

Table 2. Location information for sites used for mapping Phragmites australis, also commonly called roseau cane (RC), in the Delta National Wildlife Refuge, Louisiana.

[N, north; W, west; RC, roseau cane (P. australis); EE, elephant-ear (Colocasia esculenta); SpC, (Spartina cynosuroides)]

\begin{tabular}{lllcccl}
\hline $\begin{array}{c}\text { Site } \\
\text { number } \\
\text { (fig. 2) }\end{array}$ & \multicolumn{1}{c}{ Site name, 2018 } & \multicolumn{1}{c}{ Site name, 2019 } & $\begin{array}{c}\text { Latitude, } \\
\text { in digital } \\
\text { degrees N }\end{array}$ & $\begin{array}{c}\text { Longitude, } \\
\text { in digital } \\
\text { degrees W }\end{array}$ & $\begin{array}{c}\text { Latitude, in degrees, } \\
\text { minutes, seconds }\end{array}$ & $\begin{array}{c}\text { Longitude, in } \\
\text { degrees, minutes, } \\
\text { seconds }\end{array}$ \\
\hline S1 & S1_RCGrn1 & S1_RC_EEMix & 29.24042 & -89.16193 & $29^{\circ} 14^{\prime} 25.5012^{\prime \prime}$ & $-89^{\circ} 9^{\prime} 42.9588^{\prime \prime}$ \\
S2 & S2_RC_EEMix & S2_RC_EEMix & 29.23518 & -89.16855 & $29^{\circ} 14^{\prime} 6.6582^{\prime \prime}$ & $-89^{\circ} 10^{\prime} 6.7794^{\prime \prime}$ \\
S3 & S3_RC_EE & S3_EE_RC & 29.23487 & -89.16855 & $29^{\circ} 14^{\prime} 5.5212^{\prime \prime}$ & $-89^{\circ} 10^{\prime} 6.7794^{\prime \prime}$ \\
S5 & S5_RC2 & S5_RC & 29.29067 & -89.19718 & $29^{\circ} 17^{\prime} 26.4006^{\prime \prime}$ & $-89^{\circ} 11^{\prime} 49.8582^{\prime \prime}$ \\
S6 & S6_RC3 & S6_RC & 29.31067 & -89.16995 & $29^{\circ} 18^{\prime} 38.4006^{\prime \prime}$ & $-89^{\circ} 10^{\prime} 11.82^{\prime \prime}$ \\
S7 & S7_EE & S7_EE & 29.27838 & -89.21092 & $29^{\circ} 16^{\prime} 42.1788^{\prime \prime}$ & $-89^{\circ} 12^{\prime} 39.3006^{\prime \prime}$ \\
S8 & S8_RC4 & S8_RC & 29.27723 & -89.21768 & $29^{\circ} 16^{\prime} 38.0382^{\prime \prime}$ & $-89^{\circ} 13^{\prime} 3.6582^{\prime \prime}$ \\
S9 & S9_RC_SpCMix & S9_RC_SpC_EE & 29.26820 & -89.22532 & $29^{\circ} 16^{\prime} 5.52^{\prime \prime}$ & $-89^{\circ} 13^{\prime} 31.1412^{\prime \prime}$ \\
S10 & S10_RC5 & Site not reoccupied & 29.30055 & -89.25120 & $29^{\circ} 18^{\prime} 1.98^{\prime \prime}$ & $-89^{\circ} 15^{\prime} 4.3194^{\prime \prime}$ \\
S11 & S11_MixRC_EE & Site not reoccupied & 29.18607 & -89.19382 & $29^{\circ} 11^{\prime} 9.8412^{\prime \prime}$ & $-89^{\circ} 11^{\prime} 37.7406^{\prime \prime}$ \\
S12 & S12_RC_EE & Location change & 29.18393 & -89.19455 & $29^{\circ} 11^{\prime} 2.1582^{\prime \prime}$ & $-89^{\circ} 11^{\prime} 40.38^{\prime \prime}$ \\
S12_19 & Location change & S12_RC_EEMix & 29.18889 & -89.19318 & $29^{\circ} 11^{\prime} 19.9998^{\prime \prime}$ & $-89^{\circ} 11^{\prime} 35.4588^{\prime \prime}$ \\
S13 & S13_Mud_Water ${ }^{\prime \prime}$ & Location change & 29.18377 & -89.19503 & $29^{\circ} 11^{\prime} 1.5606^{\prime \prime}$ & $-89^{\circ} 11^{\prime} 42.1182^{\prime \prime}$ \\
S13_19 & Location change & S13_RC_EE & 29.18457 & -89.19405 & $29^{\circ} 11^{\prime} 4.4412^{\prime \prime}$ & $-89^{\circ} 11^{\prime} 38.58^{\prime \prime}$ \\
\hline
\end{tabular}

${ }^{1}$ Mud and water field data were collected at the same site. 


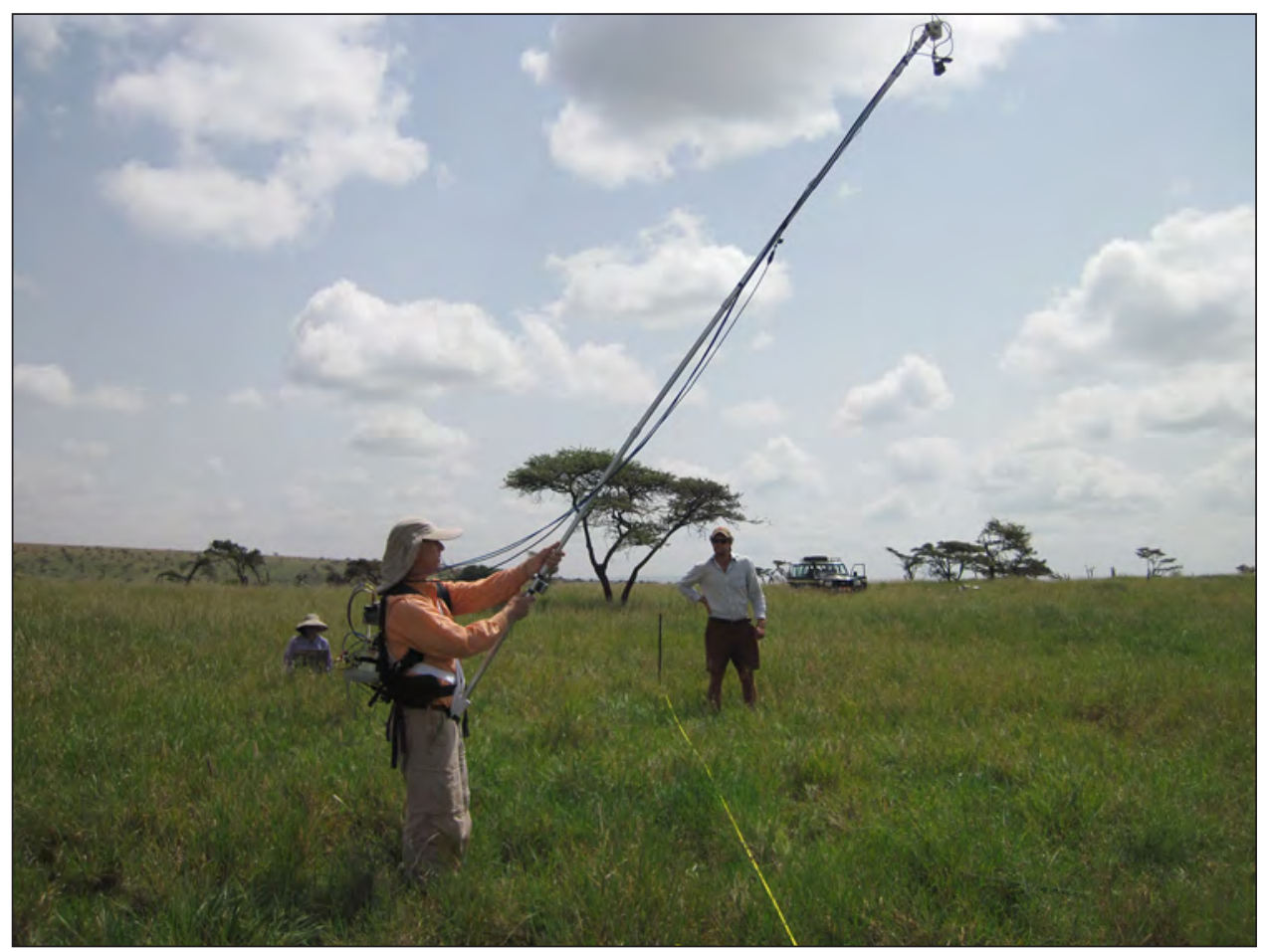

Figure 3. Field collection of reflectance spectra and webcam images. The two radiometers and webcam mounted at the end of the pole are positioned vertical to the surface. The radiometer faced upward collects the sunlight, and the other faced downward collects the surface-reflected sunlight. The webcam faces downward. All three measurements are collected simultaneously. Photograph by Samson Kuraru, GIS Analyst, Northern Rangelands Trust.

2018, 10 of the 12 instrumented field sites were completely or predominantly composed of $P$. australis marsh. One site was completely covered by Colocasia esculenta (elephantear), one site was covered by mud, and one site was covered by water. In 2019 , only 3 of the 10 sites were completely or predominantly composed of $P$. australis marsh, while the rest of the sites were heavily mixed with or completely covered by elephant-ear. In addition, in 2018 and 2019, there were four and five observation sites, respectively, without instrument data collection. At all sites, Global Positioning System coordinates and photographic and field note descriptions were obtained. At sites with instrument data collection, field radiometer and webcam photography were collected (fig. 3).

\section{Field Simulation of Satellite VI Data}

Field radiometers were used to simulate the collected satellite data. The dual radiometer system measured reflected sunlight from an approximate 3.5-m-diameter GSA while simultaneously recording the sunlight illuminating the same ground area (Rundquist and others, 2014; Rangoonwala and Ramsey, 2019). Simultaneous collection of illuminating and reflecting sunlight measurements improves the ability to collect quality reflectance data even during variable cloudy conditions. Also, the enlarged GSA presents a truer representation of the vegetated canopy reflectance than the commonly used $\leq 1$-m-diameter GSA, thus improving the field- and satellitemeasured reflectance correspondence. These GSA calculations are representative of short vegetation, so the $P$. australis marsh extent captured by the radiometer is altered when $P$. australis reaches heights over $3 \mathrm{~m}$.

At the apex of the radiometer above the ground surface, the downward-facing radiometer captures reflected light from about a 1.4-m-diameter GSA that includes the highest $P$. australis leaves reaching up to about $4 \mathrm{~m}$. From the apex, the GSA increases as the above-canopy distance decreases until reaching the approximate 3.5-m-diameter GSA at the ground surface. Although the radiometer sampling provides a good representation of the $P$. australis marsh reflectance, the contribution of the lower unshaded leaves to the reflectance could be weighted higher than the tallest $P$. australis marsh leaves. Because a satellite optical sensor perceives full areal cover, that unequal weighting in the field reflectance may affect the field to satellite reflectance magnitude comparison, and ultimately, the field VI and LFC calibration transfer to the satellite VI.

An important component of the mapping is how well the VI calculated from the satellite reflectance represents the field VI calculated from field reflectance data. To that end, field reflectance data were extracted within Sentinel-2A spectral 
bandwidths (European Space Agency, Sentinel-2 Spectral Response Functions, 2018) and used to calculate the field VI (fig. 4). This method optimizes the representation of satellite surface reflectance to the photographic LFC.

\section{Vegetation Live Fractional Cover Classification}

The webcam photography was vital in visual documentation of the $P$. australis and dead component spatial distributions, elephant-ear occurrences, background soil or water exposures, and, central to this project, the LFC. The webcam system mounted at the same point as the radiometer obtained an approximate 4-m by 6-m red-green-blue picture of the canopy coincident with the radiometer measurement (fig. 4). The common point of view provided the radiometer GSA (at ground level) and webcam photography near exact overlap (fig. 5).
We applied the method used in separating live and dead biomass in clip biomass samples to classify the vegetation as live or dead (Rangoonwala and Ramsey, 2019). That separation criterion designates a stem or leaf as live if any part exhibits a green color. To obtain that separation, criterion thresholds were calculated based on the red and green bands of webcam photography. Trial and error were used to determine the lower and upper red/green photographic band ratio thresholds that performed best in classifying the live, dead, and background fractions in the photographic image (Rangoonwala and Ramsey, 2019). The red/green band ratio mimics the use of the optical VI to determine the LFC and provides a simple way to standardize the classification of the webcam photography. This classification procedure suited the photograph spectral quality, simplified the classification, and

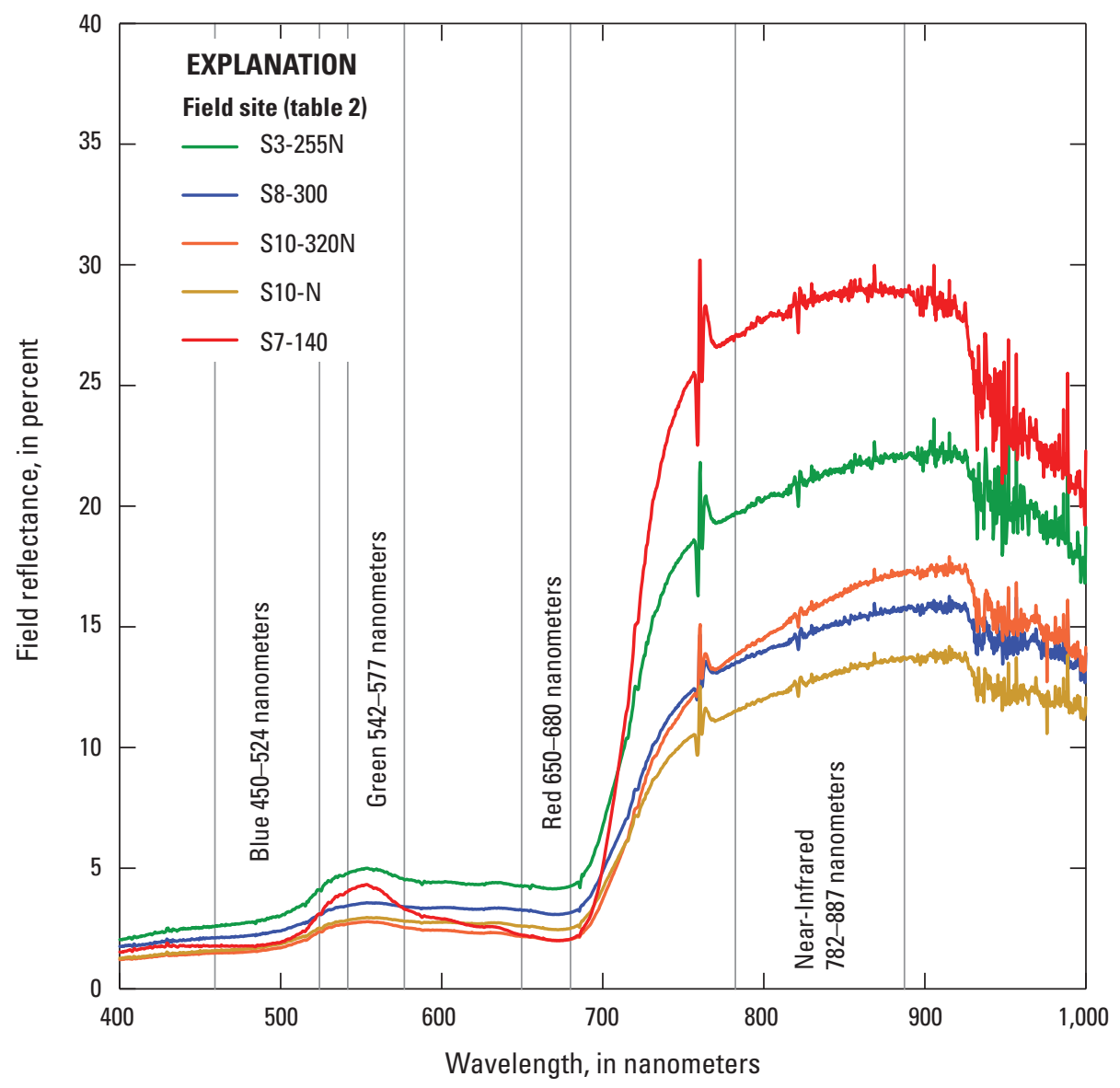

Figure 4. Reflectance spectra calculated from radiometer data collected at five field sites (fig. 2 and table 2). The satellite Sentinel-2 sensor band locations and widths are overlain on the reflectance spectra. To directly align the field data calibration with that of the Sentinel-2 calibration, field calibrations were calculated with data extracted from the field reflectance spectra based on the depicted Sentinel-2 bandwidths. Site S3 is a Phragmites and elephant-ear mixed site. Site S8 and the two locations at site $\mathbf{S 1 0}$ are pure Phragmites marsh sites, and Site $S 7$ is a pure elephant-ear site. Webcam photographs of these sites are shown in figure 5. 


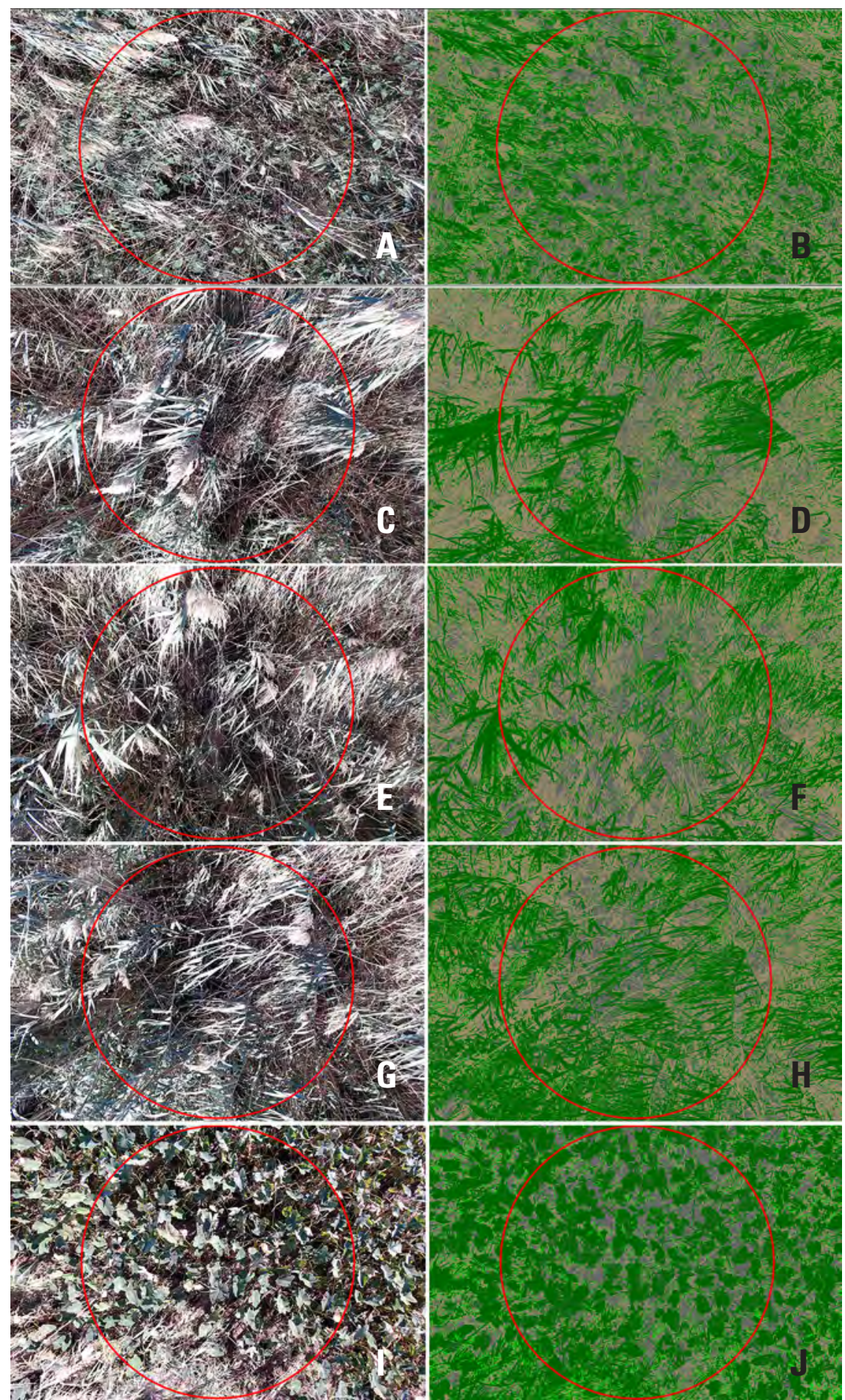

Figure 5. Webcam photographs shown on the left and its classification shown on the right. (A-B) site S3, a mixed Phragmites marsh site; (C-D) site S8 and (E-H) two locations at site S10, pure Phragmites marsh sites; and (I-J) site S7, a pure elephant-ear site. The red circle approximates the ground field-of-view of the field radiometer. unified the processing while accommodating the high spectral variability reflecting the high composition variability captured by the webcam photographs.

Challenges in using the photographic classification to represent LFC visibly green vegetation are mainly related to differences between the satellite representation and visual perception projected onto a fixed surface area at a nadir orientation. In this orientation, green vegetation lying underneath or in the shadow of green vegetation in the vertical projection of the web photography is not fully resolved. A similar restriction applies to the visible (vis, 400-700 micrometer) region of the sensor; however, NIR can aggregate information from a stack of two to three overlapping leaves (Ramsey and Jensen, 1995). As the proportion of overlapping leaves increase in a nadir projection, the LFC photographic estimate could increasingly underestimate the sensor perceived LFC.

\section{Challenges in Relating Field to Satellite Measurements}

Radiometer and webcam data were collected at two to three directions or locations at each field site. Although the boat platform was inserted as far as possible into the marsh and the radiometer and webcam were further extended into the marsh via the support pole, all sampled locations were near the open water and marsh edge. That closeness to the edge increased the possibility of boundary pixels in the satellite images being contaminated to some extent by open water.

To minimize that possible contamination, locations for data collection were preferred where the overall marsh characteristics extended at least 3 pixels, or $30 \mathrm{~m}$, beyond the edge into the interior. While that criteria tended to minimize edge-pixel contamination, higher water levels increased the variance of the satellite measurements. Further, the relation of water level and interior flooding varied spatially throughout the Delta NWR.

Although the larger radiometer fieldof-view increased the surface to satellite measurement correspondence to nearly 
40 percent, the variable influence of surface water and lack of consistent field to satellite measurement alignment heightened the variance in the field to satellite correspondence.

\section{Water Mask Creation and Above-Surface Water Levels}

A water mask was created from a mix of optical and SAR images that visually best- preserved $P$. australis marsh while eliminating intermittently ponded water bodies and most bare and vegetated mud flats. Because the primary study objective was to develop a $P$. australis marsh LFC mapping system, in all but a few cases where extreme high water existed, the same water mask was applied to all map products.

Above the marsh surface, water levels at four Coastal Protection and Restoration Authority (CPRA) stations (CPRA, 2018) within the Delta NWR were documented at the times of all satellite image collections (table 1). Optical remote sensing is sensitive to subcanopy flooding (Ramsey and others, 2013); the higher the water level relative to the canopy height, the higher the influence of water on the optical data. Although the spatial extent represented by each Louisiana Coastwide Reference Monitoring System (CRMS) site is not implied, general correspondence of high water across multiple CRMS sites indicates needed caution in interpretation of the optical data values.

\section{Results}

\section{Field Reflectance Spectra}

Excluding the mud and water sites, usable reflectance spectra were obtained at 24 locations at 11 marsh sites in 2018 and at 29 locations at 10 marsh sites in 2019. In both years, from 5 to 7 sets, each set containing 25 upwelling and downwelling light spectra, were used to produce each site-location average. The spectra exhibit high variance in magnitude and form. The variance reflects the sensitivity of reflectance to composition variability between sites and even within sites where reflectance measurements were obtained at multiple locations.

Spectra from 2018 presented in figure 4 provide examples of changing compositions as represented in the average site-location reflectance spectrum. For instance, the average reflectance spectrum of site 3 represents a mixture of $P$. australis and elephant-ear as compared to reflectance spectra from pure $P$. australis at sites S8 and S10 and pure elephantear at site S7. The spectral alignment of field to Sentinel-2 reflectance data was assured by use of field reflectance data calculated based on the Sentinel-2 bands shown overlain on the plotted spectra.

\section{NDVI and MSAVI2 Representation of Field LFC}

The comparison of NDVI and MSAVI2 effectiveness in representing field LFC was based on 2018 field and satellite data collections. Results showed that both NDVI and MSAVI2 produce significant $(\mathrm{p}<0.001)$ representations of field LFC; however, the usable MSAVI2 range was severely limited in prediction of LFC, and NDVI provided a much broader usable range of LFC prediction. While the NDVI and MSAVI2 comparison was limited, the indicated broader range functionality of NDVI provided a more appropriate basis for mapping LFC. NDVI was selected as the basis for creating the LFC status and change maps.

\section{Sentinel-2 NDVI Calibrated to Field NDVI Data}

The 2018 and 2019 field and satellite-NDVI data were combined to derive the field-NDVI to satellite-NDVI calibration; this combination produced a regression calibration with a coefficient of determination $\left(\mathrm{R}^{2}\right)$ of 0.73 and a root-meansquare error RMSE of \pm 5.22 (eq. 1; fig. 6). This calibration was used to convert the Sentinel-2 and Landsat satelliteNDVIs to their field-NDVI equivalents for 53 observations.

$$
\text { field }_{N D V I}=0.96 \text { satellite }_{N D V I}-3.16
$$

$$
\begin{aligned}
& \text { where } \\
& \text { field }_{N D V I} \\
& \text { satellite }_{N D V I}
\end{aligned}
$$

\section{Live Fractional Cover Classification}

In 2018, at 19 of the 24 marsh-site locations, the constant two-ratio threshold solution suitably classified the webcam photography into three classes: low-live, middle-mixed, and high-dead plus background. The LFC estimate was restricted to the low class at these sites. For the five site locations, the ratio thresholds were adjusted, and the low and middle classes were combined as the LFC.

In 2019, the same constant two-ratio threshold classification of the webcam photography was used. The same tworatio thresholds used in 2018 were used for 18 of the 29 site locations, and a slightly varied two-ratio threshold was applied to the remaining 11 site locations. In all cases, the threshold classifications provided a good visual representation of LFC.

\section{Calibration of Field NDVI to $P$. australis LFC}

Field-NDVI to LFC produced a nonlinear regression calibration with an $\mathrm{R}^{2}$ of 0.75 and a RMSE prediction error of \pm 2.25 (eq. 2; fig. 7) (NLIN Procedure SASTM). The satelliteNDVI image data calibrated to field-NDVI image data from 53 observations (eq. 1) were substituted into equation 2 to produce the LFC maps. 


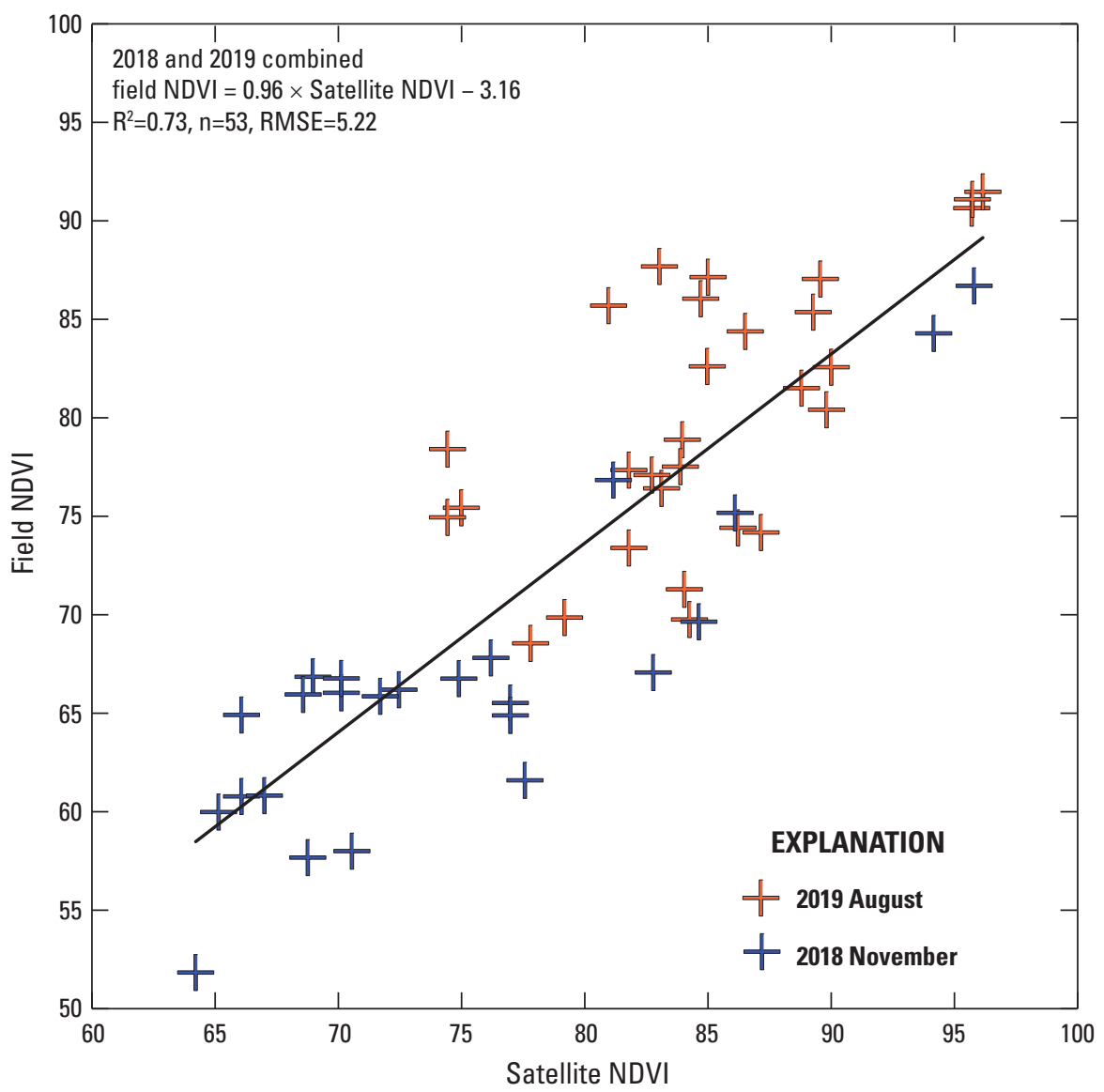

Figure 6. The correspondence between the normalized difference vegetation index (NDVI) calculated from site-location averaged field reflectance data and from site Sentinel-2 satellite reflectance data.

$$
\text { field }_{L F C}=5.415 \mathrm{EXP}\left(0.0301 \text { field }_{N D V I}\right)
$$

where

field $_{L F C}$ is the LFC classified by webcam photography,
and field $_{N D V I}$ is the satellite-NDVI.

\section{Sentinel-2 LFC Mapping Extended to Landsat}

Comparability of the September 20, 2016, Sentinel-2 and September 30 Landsat NDVI images was assessed quantitatively by using a linear regression and frequency distributions and qualitatively by visual inspection of tonal patterns. A 0.125 sample rate applied to the Sentinel-2 and Landsat full Deltaic coverages resulted in 89,388 observations (SASTM). Those observations input into a linear regression produced an $\mathrm{R}^{2}$ of 0.54 and RMSE of \pm 8.54 (eq. 3) (SAS ${ }^{\mathrm{TM}}$ ).

$$
\text { Sentinel2 NDVI }=0.82 \text { Landsat } N D V I+15
$$

The frequencies and percentages of 2016 Landsat NDVI and the 2016 Sentinel-2 NDVI representing the Mississippi River Delta land area and the Delta NWR P. australis are graphed in figures $8 A$ and $8 B$, respectively, for comparison. As shown in equation 3 , the overlays show a positive offset of the Sentinel-2 NDVI in comparison with the Landsat NDVI distribution. As seen in figure 9, the Sentinel-2 NDVI magnitude is higher than the Landsat NDVI magnitude as reflected in equation 3. The Sentinel-2 detail is higher than Landsat's because Landsat has only a 30-m spatial resolution, whereas Sentinel-2's resolution is $10 \mathrm{~m}$. Even with the difference in spatial resolution, Sentinel-2 and Landsat NDVI patterns and feature appearances were similarly represented at moderate scales. Although quantitative comparability is not achieved, the high linear alignment $(0.82$, eq. 3$)$ and the visual and frequency-distribution comparability appear sufficient to support calibration of Landsat NDVI to LFC based on the Sentinel-2 calibration equations 1 and 2 (fig. 10). The expectation is that Landsat LFC will visually represent the long-term and more distinct changes in $P$. australis LFC that simulates Sentinel-2 LFC mapping. 


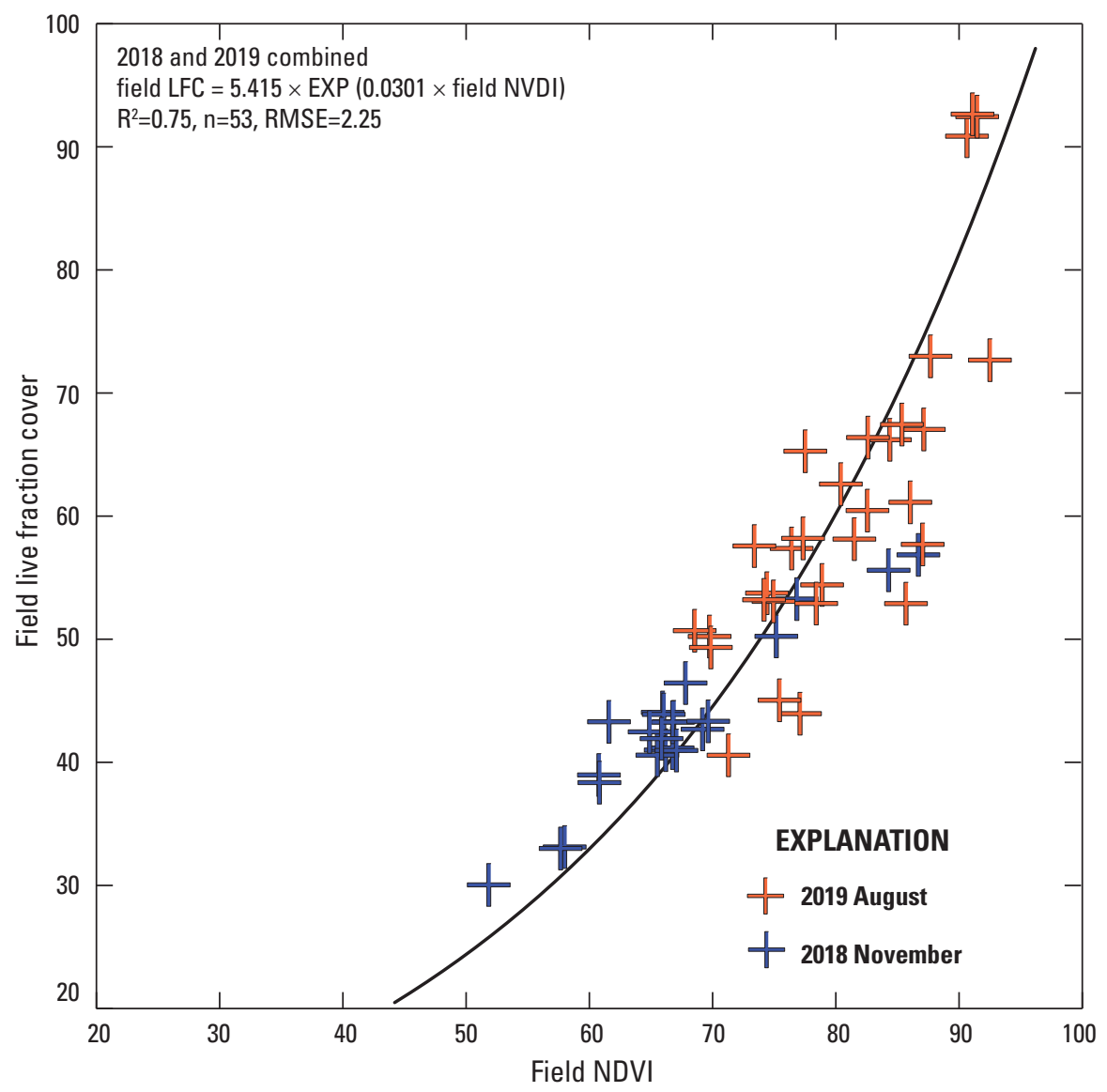

Figure 7. The best-fit nonlinear regression model (equation 3) between the field normalized difference vegetation index (NDVI) calculated from field reflectance data and webcam live fractional cover (LFC) classifications.
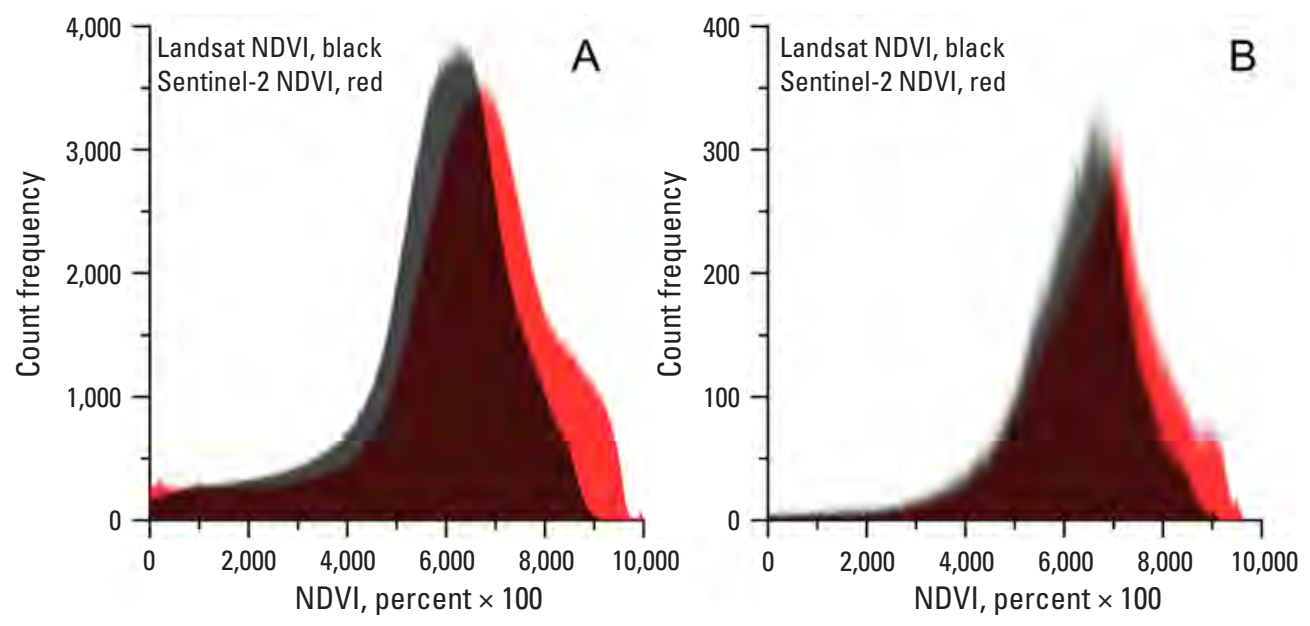

Figure 8. The September 30, 2016, Landsat count frequencies overlain on the September 20, 2016, Sentinel-2 normalized difference vegetation index (NDVI) count frequencies for $(A)$ the Mississippi River Delta, Louisiana, and $(B)$ the Phragmite marshes at the U.S. Fish and Wildlife Service Delta National Wildlife Refuge, Louisiana. 

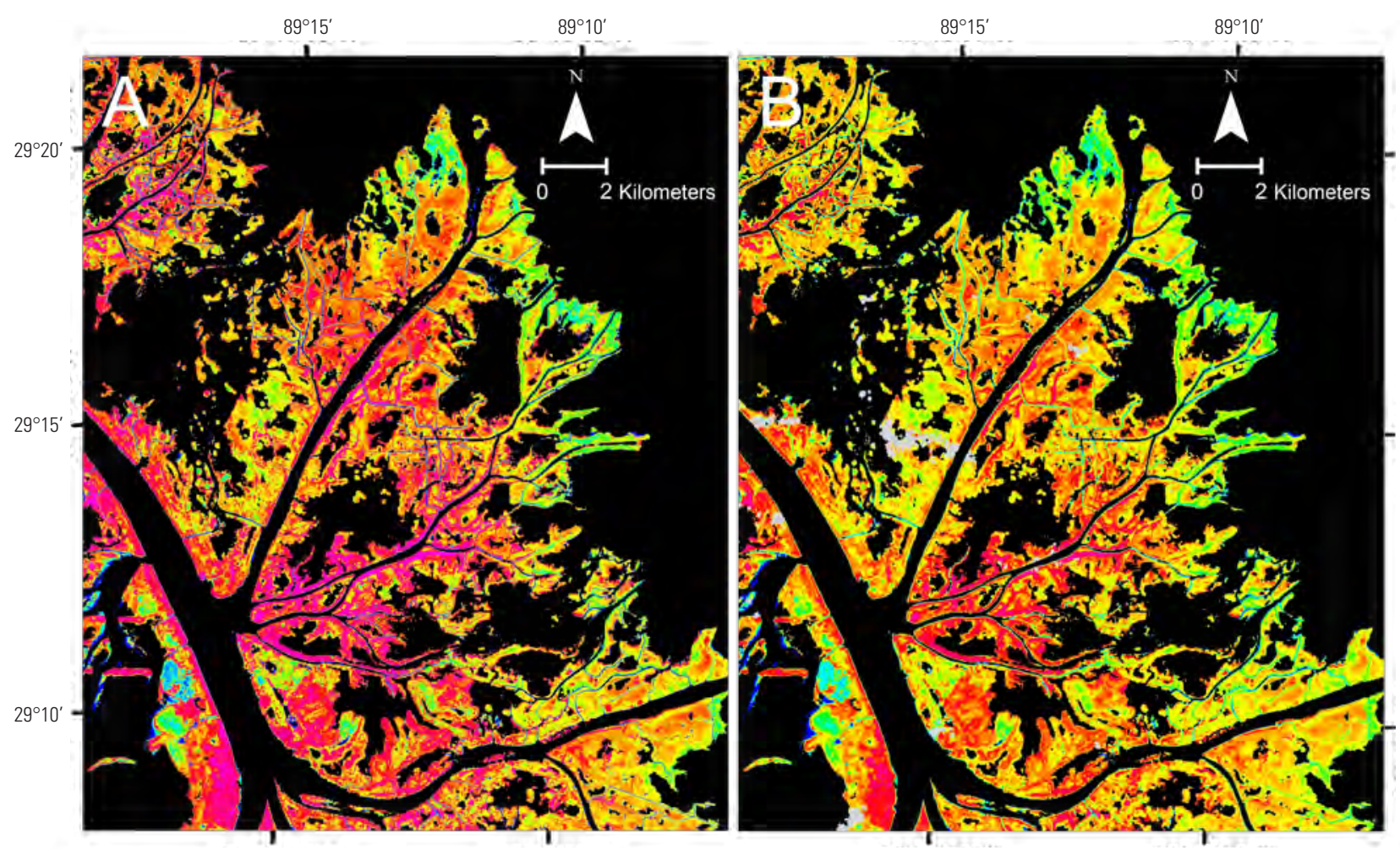

Figure 9. The $(A)$ September 20, 2016, Sentinel-2 normalized difference vegetation index (NDVI) and (B) September 30, 2016, Landsat NDVI, U.S. Fish and Wildlife Service Delta National Wildlife Refuge, Louisiana. Blues to greens denote low to medium-low NDVIs, light green represents +/- medium NDVls, yellows to reds signify increasing NDVI, and the highest NDVIs are shown in pink.

\section{LFC Status and Change Maps}

Continuous classification maps showing LFC status (single date) and change (between two dates) were produced (Rangoonwala and Ramsey, 2020). All LFC status-map ranges were represented as a continuous color gradient from brown to yellow-green. Although the two-color gradient best represents the status of LFC, the color rendition of mapped LFC differences between dates was applied to emphasize those differences. As in the two-color gradient, a continuous color gradient is again used; however, the color ramp is more vivid than the two-color gradient. Greens bridge the LFC increase and decrease range, pinks and reds reflect the highest decreases, and blues the highest increases between two dates. The same color representations are applied throughout all maps ensuring direct comparability among all LFC status and change maps.

\section{Landsat Historic LFC Mapping}

Landsat LFC status (table 1) and change (table 3) maps are available in Rangoonwala and Ramsey (2020).

The yearly Landsat LFC status and change maps exhibited stability throughout 2009-16. Extreme LFC changes were localized and uncommon.
Although contained within a moderate range, Landsat LFC status maps identified abnormal changes and shifting patterns. For example, the moderate differences exhibited between the May 25, 2010, and June 13, 2011, LFC maps are intensified in the LFC change map (figs. 11-13). LFC maps represent a more extensive change as depicted in the July 26, 2015, and September 30, 2016, LFC change map (Rangoonwala and Ramsey, 2020). While some higher and more extensive differences were found, most year-to-year LFC variability was of lower magnitudes and largely local, thus giving rise to shifting LFC spatial patterns between dates. Notably, LFC status differences could be prominent even between two summer, or near summer, months of the same year (for example, April 23 and September 30, 2016; Rangoonwala and Ramsey, 2020). Within the generally stable period of 2009 to 2017, the Landsat LFC status and change mapping identified periods of moderate and extensive change, revealed the existence of high local variability of low magnitude, and showed that LFC can change substantially over short time periods (Rangoonwala and Ramsey, 2020). 

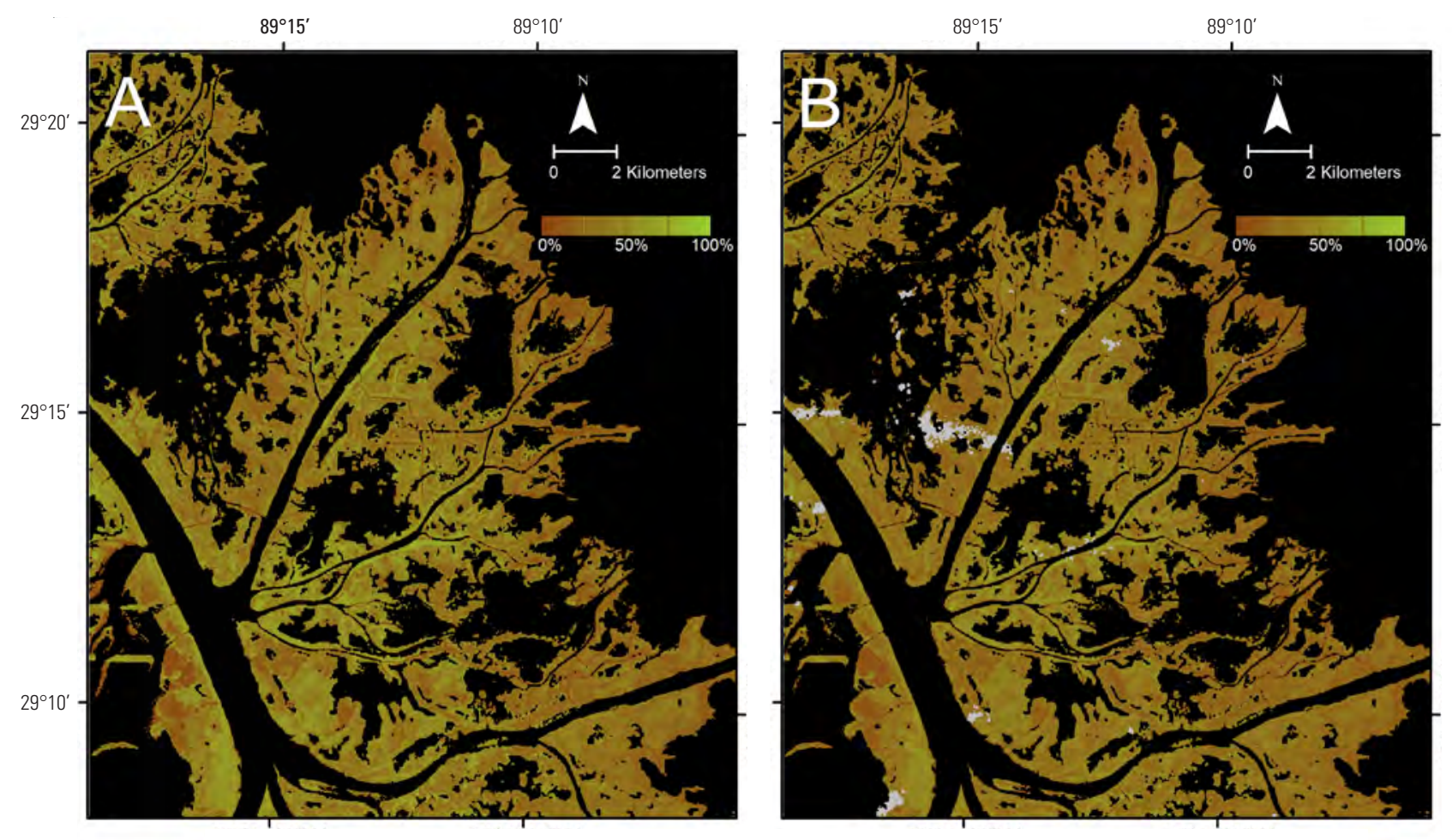

Figure 10. Comparison of 2016 Sentinel-2 and Landsat Live Fractional Cover (LFC) maps centered on the Delta NWR from the $(A)$ September 20, 2016, Sentinel-2 LFC and (B) September 30, 2016, Landsat LFC maps. LFC increases from brown to yellow-green. Color tones represent the same LFC values in both $A$ and $B$.

Table 3. Landsat Live Fractional Cover change maps of the lower Mississippi River Delta.

\begin{tabular}{ll}
\hline \multicolumn{1}{c}{ Earlier Landsat map } & \multicolumn{1}{c}{ Later Landsat map } \\
\hline June 23, 2009 & May 25, 2010 \\
June 23, 2009 & September 30, 2010 \\
May 25, 2010 & June 13, 2011 \\
September 30, 2010 & October 3, 2011 \\
June 13, 2011 & October 24, 2013 \\
October 3, 2011 & October 24, 2013 \\
October 24, 2013 & May 20, 2014 \\
May 20, 2014 & July 26, 2015 \\
November 28, 2014 & July 26, 2015 \\
July 26, 2015 & September 30, 2016 \\
October 14, 2015 & September 30, 2016 \\
April 23, 2016 & May 28, 2017 \\
\hline
\end{tabular}




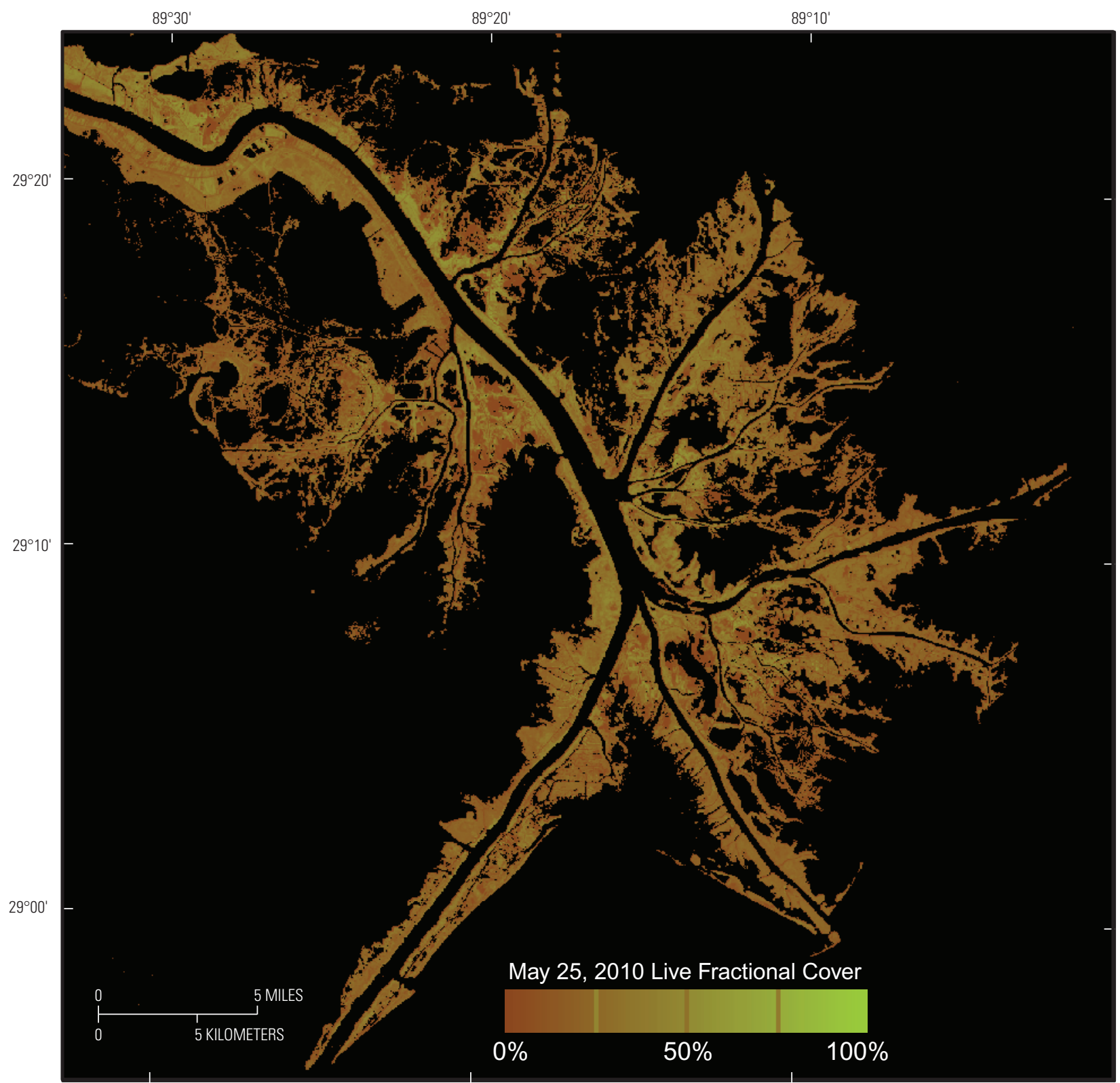

Figure 11. Landsat live fractional cover (LFC) for the lower Mississippi River Delta, Louisiana, May 25, 2010. LFC status is represented as a 0 percent to 100 percent continuous color gradient from brown to yellow-green. Note the high LFC spatial variability throughout the lower Mississippi River Delta.

\section{Sentinel-2 LFC Mapping}

All Sentinel-2 LFC status (table 1) and change maps (listing in table 4) are contained in Rangoonwala and Ramsey (2020).

The 2016, 2017, 2018, and 2019 Sentinel-2 LFC status maps exhibit overall low differences from year to year (table 1) (Rangoonwala and Ramsey, 2020). These differences are emphasized in the LFC change maps from 2016 to 2017 , 2017 to 2018, and 2018 to 2019 (table 4) (Rangoonwala and Ramsey, 2020). In addition, in figures 14, 15, and 16, even though 2017 LFCs (fig. 15) are overall lower than 2016 and
2018 LFCs (figs. 14 and 16), this change is not ubiquitous. LFCs that are slightly higher in 2017 (fig. 15) than in 2016 (fig. 14) occur in small areas and are more pronounced to the east of the NWR. Similarly, scattered yellows in the 2017-2018 LFC change map signify some higher LFCs in 2017 (fig. 17).

LFC differences are pronounced in the seasonal May, July, October, and December 2018 status and change maps (Rangoonwala and Ramsey, 2020). Surprisingly, in the December to October 2018 LFC change map (Rangoonwala and Ramsey, 2020) there are scattered areas exhibiting little change. High seasonal LFC spatial heterogeneity is also 


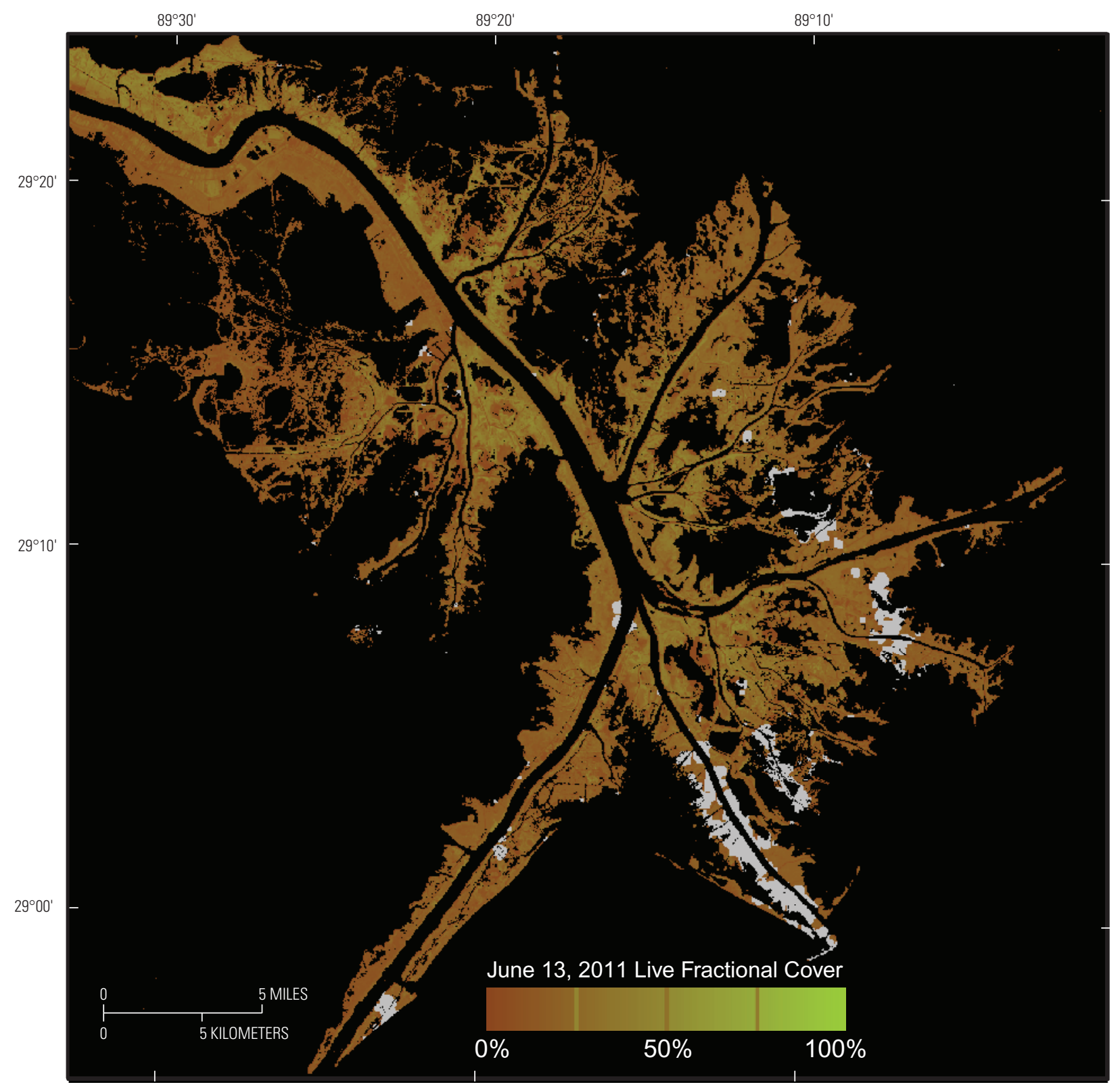

Figure 12. Landsat live fractional cover (LFC) for the lower Mississippi River Delta, Louisiana, June 13, 2011. LFC status is represented as a 0 percent to 100 percent continuous color gradient from brown to yellow-green. As in figure 11, although the LFC is mostly about 50 percent, there is a low amplitude and highly scattered LFC variability throughout the lower Mississippi River Delta. Clouds are shown in white.

depicted in the July, August, September, and October 2019 (Rangoonwala and Ramsey, 2020) LFC suite. As in the yearly status and change LFC maps, high spatial heterogeneity is notable in the 2018 and 2019 seasonal LFC and LFC change maps (Rangoonwala and Ramsey, 2020).

To highlight how those spatially heterogeneous changes are represented in LFC maps, a color composite containing 2016 LFC as red, 2017 LFC as green, and 2018 LFC as blue is displayed in figure 18. In the color composite, pure or nearly pure blue, green, or red hues represent where the LFC magnitude is predominantly high for one of the years. Although these high or low extremes occur, for the most part, this composite exhibits a mosaic of hues and tones that represent predominantly high LFC magnitudes in two of the years. For instance, aqua represents predominantly high LFC magnitudes for 2017 and 2018, pink represents predominantly high LFC magnitudes for 2016 and 2018, and yellow represents predominantly high LFC magnitudes for 2016 and 2017. Even though extreme events can result in unidirectional and regional change, in these 2016 to 2018 LFC maps, pervasive change is localized. Localized change indicates that differing response of the marsh to external factors is spatially variable, possibly due to differences in marsh type or exposure. This is apparent even when isolated to P. australis marsh (fig. 2). 


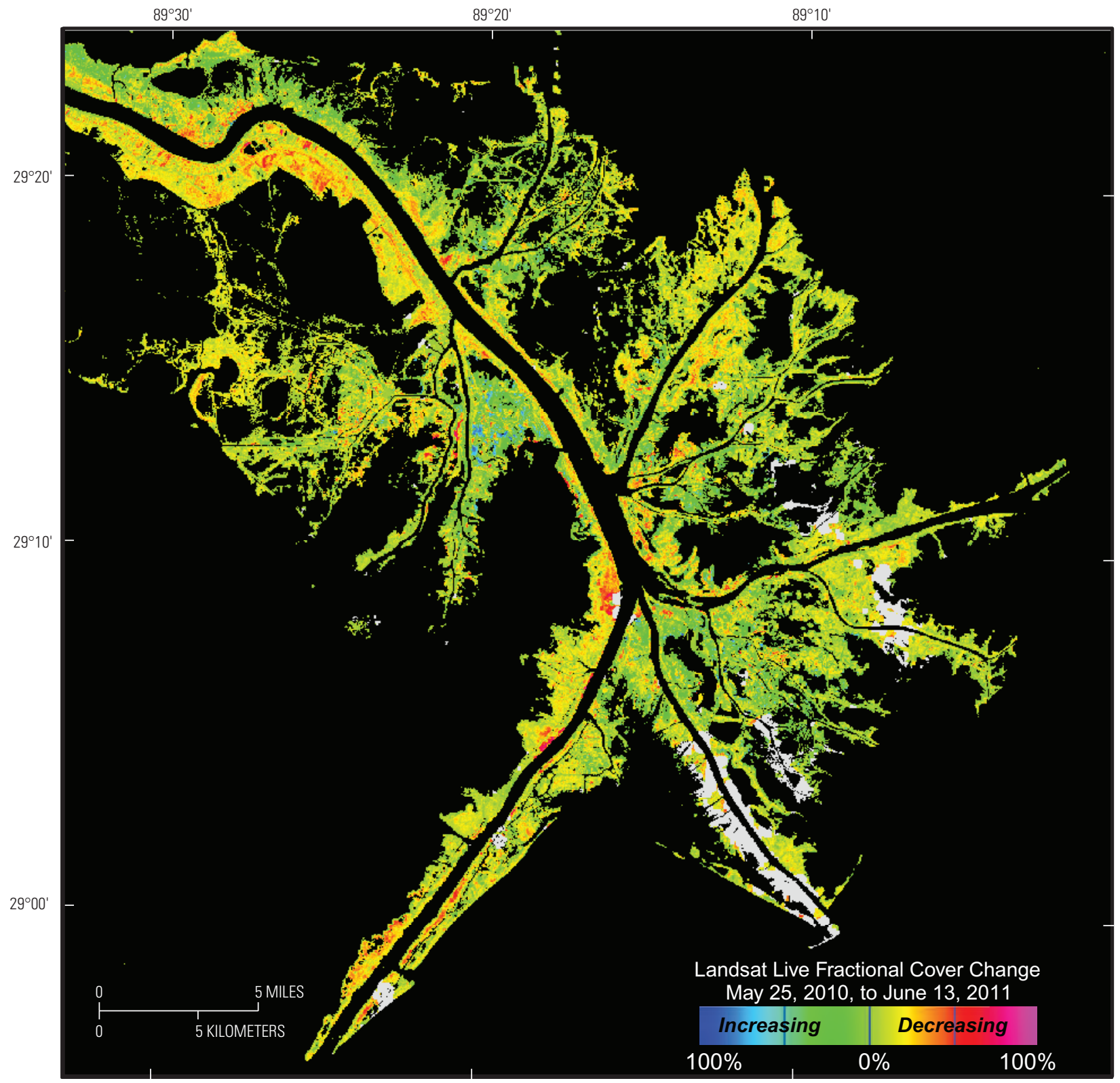

Figure 13. Landsat live Fractional Cover (LFC) change for the lower Mississippi River Delta, Louisiana, May 25, 2010, to June 13, 2011. The continuous color ramp represents LFC decrease and increase from the earlier to later date. As seen in figures 11 and 12, LFC change is overall low amplitude, centered near 0 percent. In addition, although 2010 to 2011 LFC change from inspection of figures 11 and 12 is difficult to discern, regions of LFC change direction and magnitude are easily discernable on the LFC change map. Clouds are shown in white. 


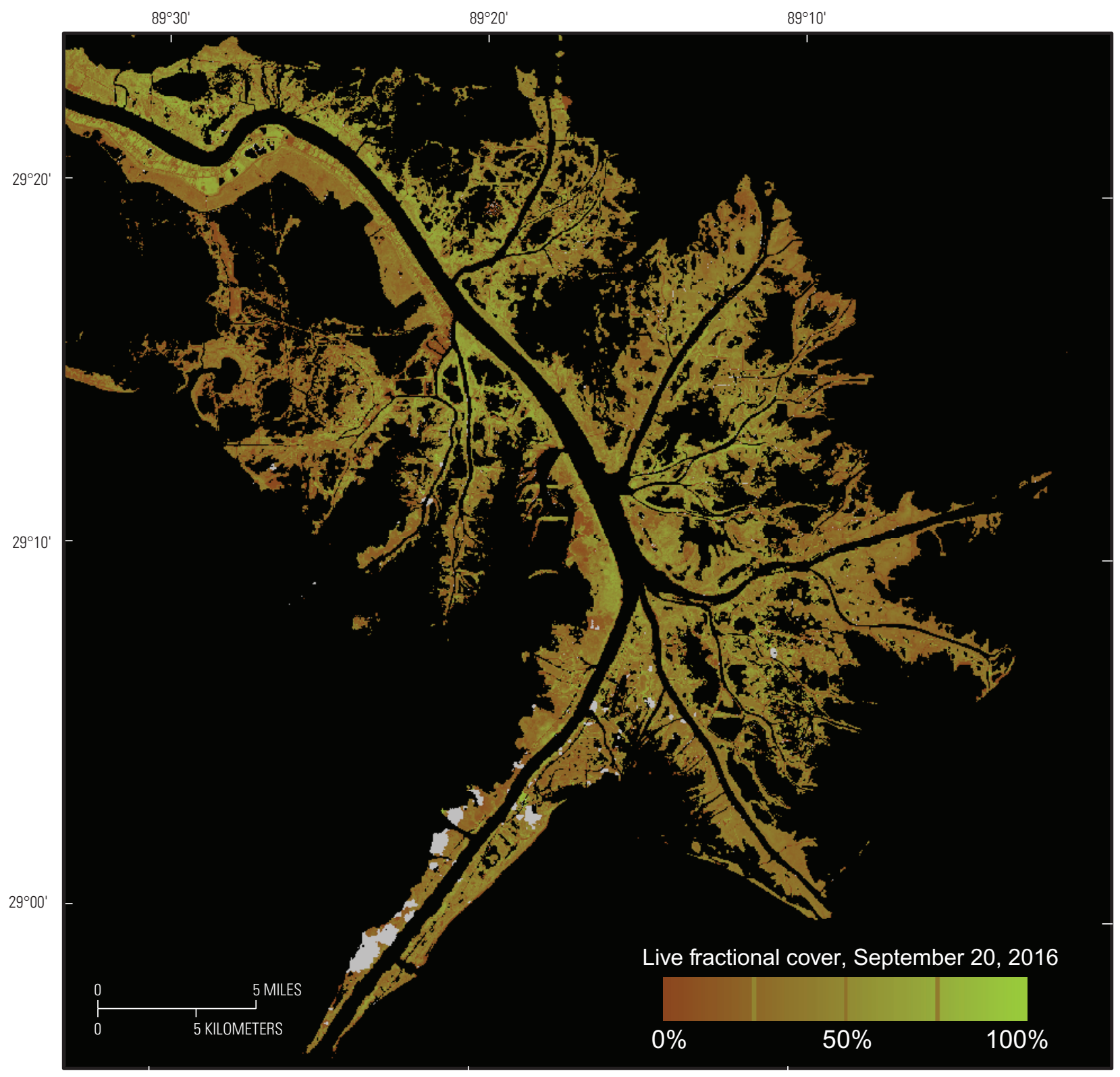

Figure 14. Sentinel-2 Live Fractional Cover (LFC) for the lower Mississippi River Delta, Louisiana, September 20, 2016. LFC status is represented as a 0 percent to 100 percent continuous color gradient from brown to yellow-green. The status map depicts an overall higher positive magnitude LFC than depicted in figures 11 and 12. Similar to figures 11 and 12, high LFC variability exists throughout the lower Mississippi River Delta. Clouds are shown in white.

Table 4. Sentinel-2 Live Fractional Cover change maps of the lower Mississippi River Delta.

[Change maps are created by subtracting the earlier date from the later date]

\begin{tabular}{ll}
\hline \multicolumn{1}{c}{ Earlier Sentinel-2 map } & \multicolumn{1}{c}{ Later Sentinel-2 map } \\
\hline September 20, 2016 & October 25, 2017 \\
October 25, 2017 & October 30, 2018 \\
October 30, 2018 & October 20, 2019 \\
May 13, 2018 & July 22, 2018 \\
October 30, 2018 & December 4, 2018 \\
\hline
\end{tabular}




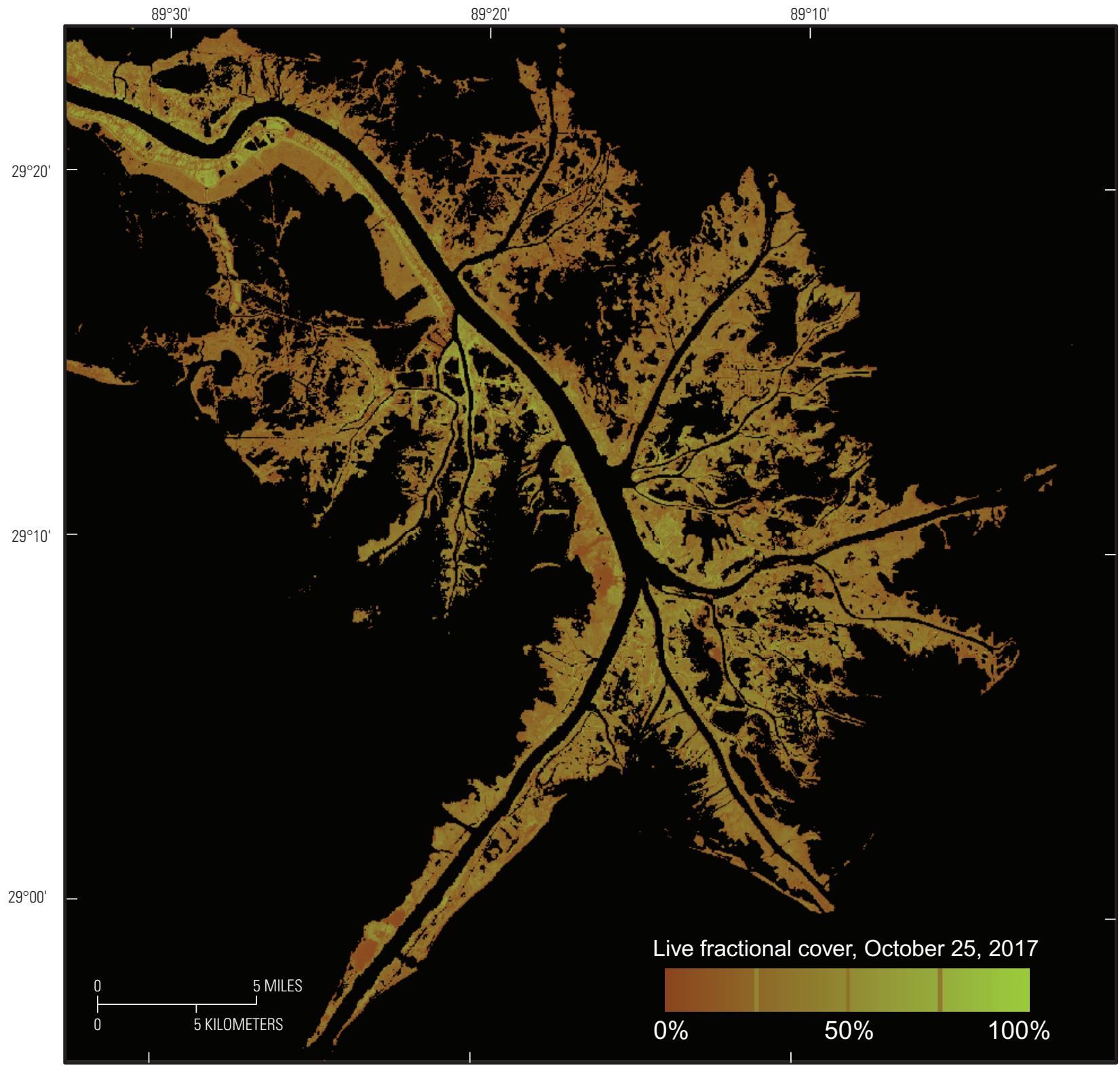

Figure 15. Sentinel-2 Live Fractional Cover (LFC) for the lower Mississippi River Delta, Louisiana, October 25, 2017. LFC status is represented as a 0 percent to 100 percent continuous color gradient from brown to yellow-green. This LFC status was captured a year later than depicted in figure 14 and shows that a noticeable decrease has occurred in overall LFC magnitude and spatial distribution from 2016 to 2017. 


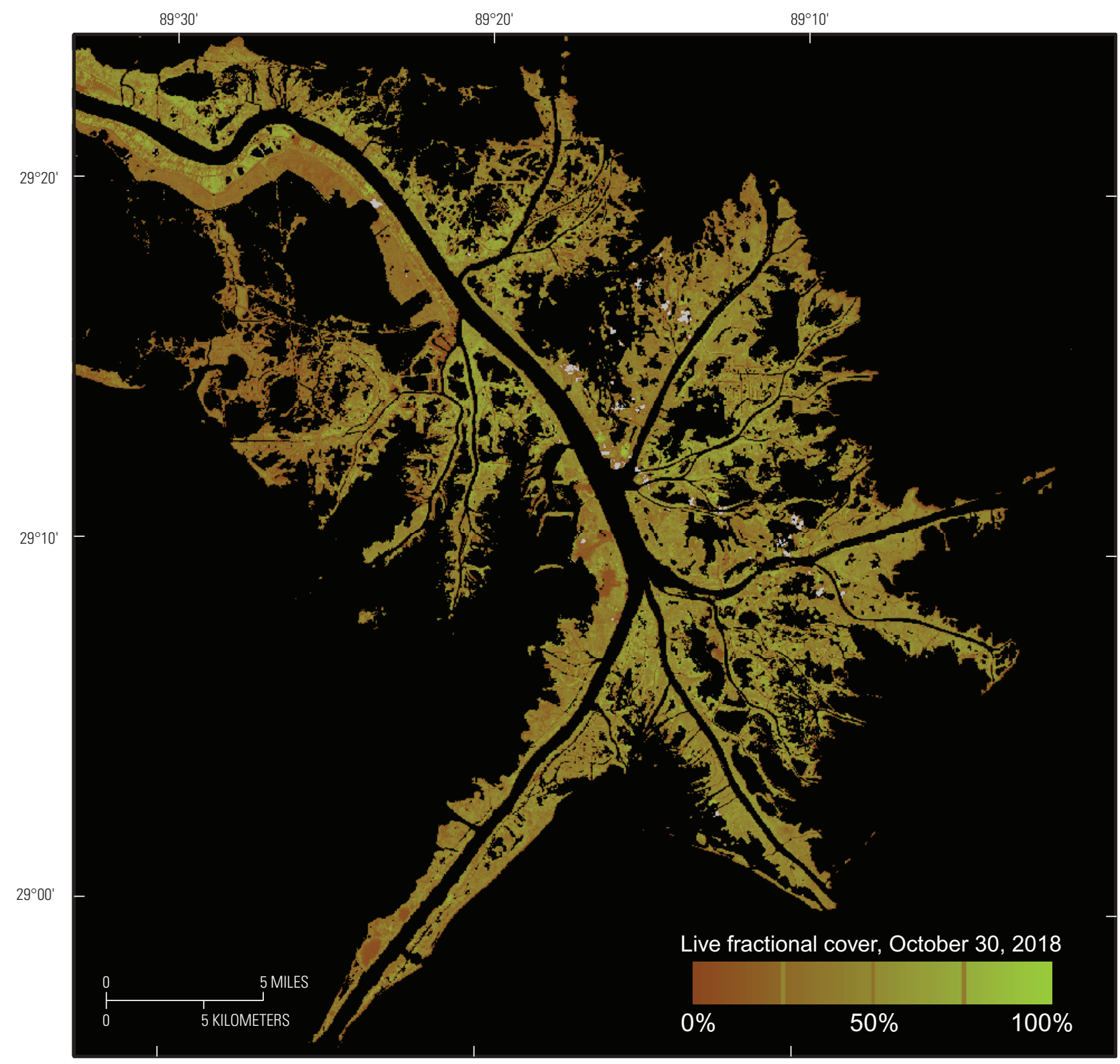

Figure 16. Sentinel-2 Live Fractional Cover (LFC) for the lower Mississippi River Delta, Louisiana, October 30, 2018. LFC status is represented as a 0 percent to 100 percent continuous color gradient from brown to yellow-green. Compared to the LFC decrease from 2016 to 2017 as depicted in figures 14 and 15, there was an overall increase in LFC from 2017 (fig. 15) to 2018. The 2017 to 2018 LFC increase exhibits a higher magnitude change than the decrease from 2016 to 2017 (figs. 14 and 15). 


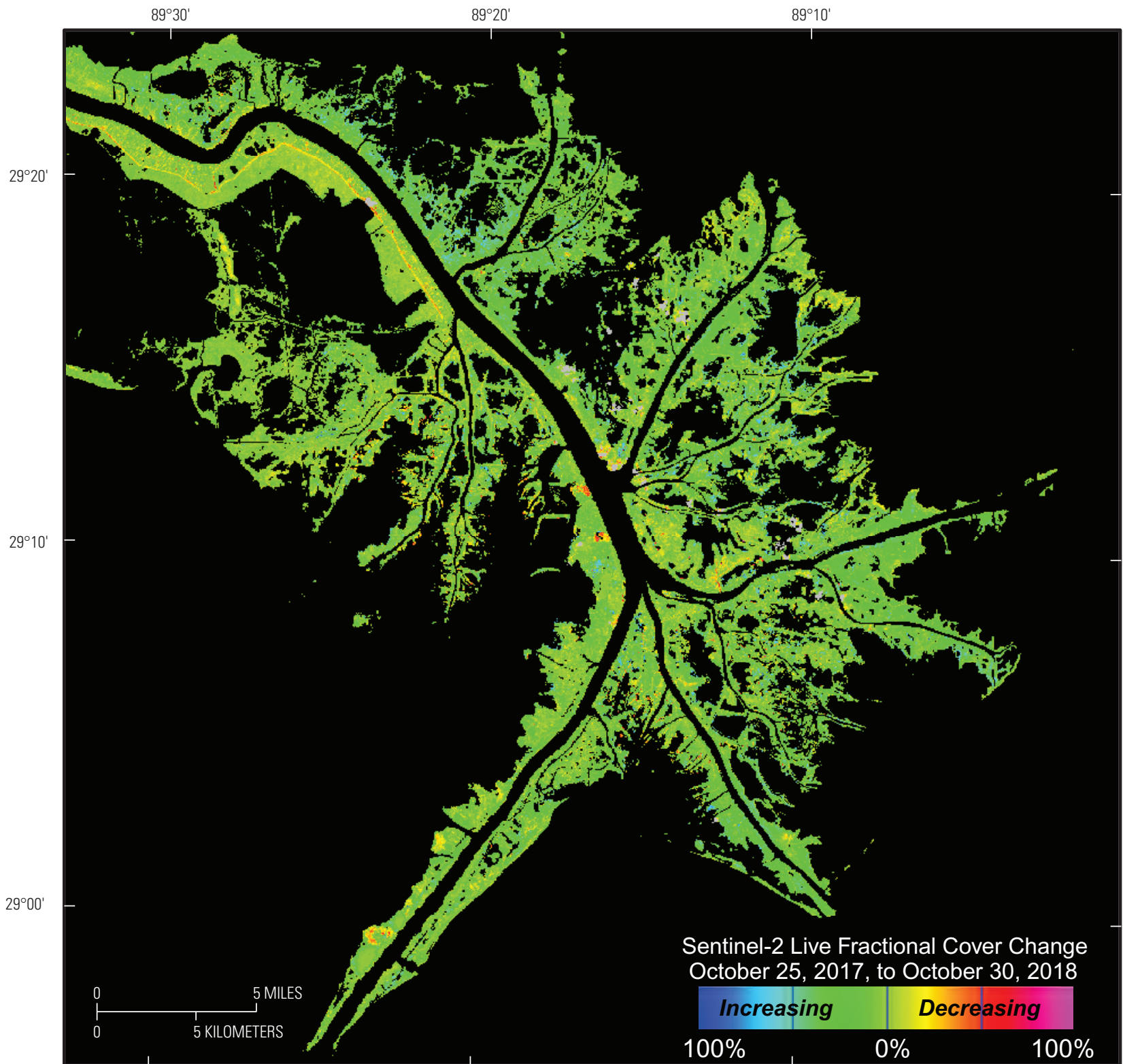

Figure 17. Sentinel-2 Live Fractional Cover (LFC) change for the lower Mississippi River Delta, Louisiana, October 25, 2017, to October 30, 2018. A continuous color gradient is used; the color ramp represents LFC decrease and increase from the earlier to later date. As indicated in figures 15 and 16, the 2017 to 2018 LFC change is overall positive throughout the lower Mississippi River Delta. In this case, the increase is substantial and largely uniform throughout, creating a nearly uniform solid green hue. 


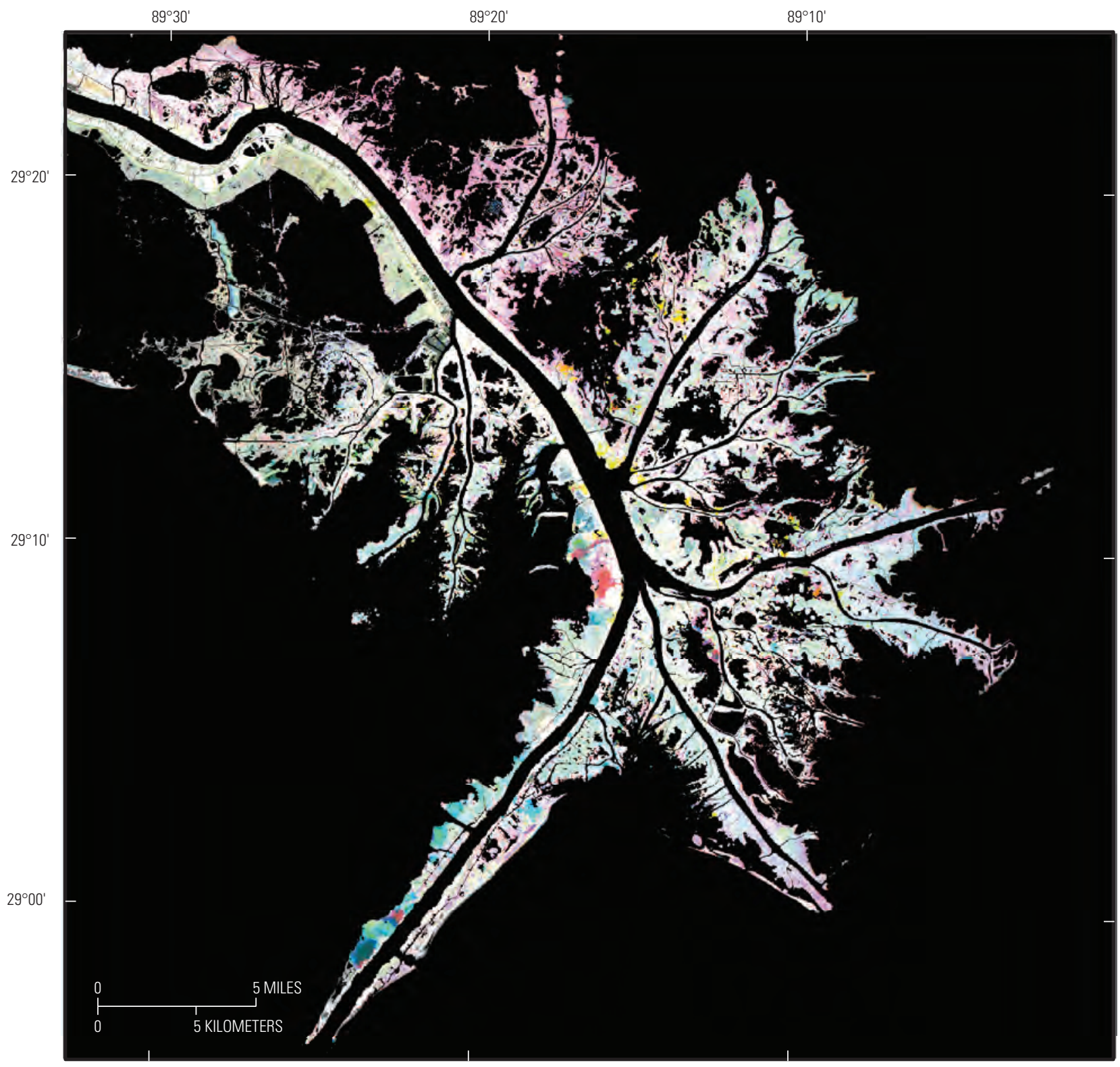

Figure 18. Sentinel-2 Live Fractional Cover (LFC) color composite displaying the 2016 LFC as red, 2017 LFC as green, and 2018 LFC as blue for the lower Mississippi River Delta, Louisiana. 


\section{Summary}

The U.S. Geological Survey, in cooperation with U.S. Fish and Wildlife Service, developed a satellite optical tool for quantitative live fractional cover (LFC) mapping for monitoring dieback of Phragmites australis in the lower Mississippi River Delta, southeastern Louisiana. The key to development of the quantitative LFC mapping was the field to satellite calibration design.

The calibration of $P$. australis marsh LFC to optical satellite image data combined field and near-in-time satellite data collections in the fall of 2018 and summer of 2019. The combination of seasons produced a calibration dataset that ranged from about 20 percent to nearly 100 percent LFC. Over that wide range, a nonlinear correspondence between the field normalized difference vegetation index (NDVI) and LFC was evident. That nonlinearity was captured by the calculated fit that replicated the well-known asymptotic feature in NDVI when reaching higher values. Basing the field-NDVI to fieldLFC and the satellite-NDVI to field-NDVI calibrations on combined early senescence and peak growth data offers nearly year-around LFC mapping.

The utility of the developed $P$. australis marsh LFC mapping tool was demonstrated by creating a yearly suite of lower Mississippi River Delta LFC status and change maps extending from 2009 to 2019. Generally, P. australis marsh LFCs were consistent in 2016, 2018, and 2019, with a somewhat lower overall LFC in 2017. In contrast, some of the highest Mississippi River Delta LFC differences were between seasons in the same year. Even within the broad and most dramatic LFC changes from October to December, scattered pockets of little to no LFC change existed in the P. australis marsh.

Comparison of close-in-time Sentinel-2 and Landsat NDVI maps showed that although the Landsat NDVI map was somewhat lower in magnitude and less detailed than the Sentinel-2 NDVI map, the NDVI spatial patterns were broadly similar. Based on that similarity, the LFC calibration based on Sentinel-2 data was applied to Landsat NDVI maps.

The 2009 to 2017 yearly Landsat status and change LFC maps showed fair stability, particularly within the U.S. Fish and Wildlife Service Delta National Wildlife Refuge (NWR), except for two periods: between May 20, 2010, and June 13, 2011, and between October 24, 2013, and May 20, 2014. Even though subtler than exhibited in the Sentinel-2 LFC maps, Landsat LFC spatial variation also was common within the Delta NWR P. australis marsh, particularly in the eastern part of the NWR.

The mapping tool is based on consistently collected and free Sentinel-2 and Landsat satellite data. The Sentinel-2 data processing can be carried out within the Sentinel Application Platform (SNAP) supported and maintained by the European Space Agency. Transfer of the SNAP-produced LFC map to the professional free QGIS platform provides the capability to analyze geographic information system data and produce publishable map products.
Following observations of replacement of $P$. australis by Colocasia esculenta (elephant-ear), elephant-ear detection was added to the development of quantifiable LFC maps. The 2018 and 2019 field reconnaissance identified a rapid increase of elephant-ear from 2018 to 2019. Based on those field assessments, satellite remote sensing detection of elephant-ear increase was initiated as part of the implementation of SAR for estimating $P$. australis marsh density. Trajectories of marsh LFC and density could provide a new tool for rapid assessment and detection of abnormal changes related to $P$. australis marsh deterioration and replacement.

\section{References Cited}

Baurick, T., 2017, Roseau cane plague on Louisiana coast might have started a year earlier: New Orleans, Louisiana, The Times-Picayune, August 12, 2017, accessed October 19, 2020, at https://www.nola.com/ news/environment/article_cc3146c2-b011-5ef1-8ac47e26b502cb4f.html.

Coastal Protection and Restoration Authority [CPRA], 2018, Coastal Information Management System (CIMS) database, accessed October 12, 2020, at https://cims.coastal.la.gov/ DataDownload/DataDownload.aspx?type=hydro_hourly.

Dugas, J.L., SooHoo, W.M., Enwright, N.M., and Couvillion, B.R., 2018, Phragmites australis maps and change, Delta National Wildlife Refuge, Louisiana (2011, 2013, 2016): U.S. Geological Survey data release, https://doi.org/ 10.5066/F7K936RG.

European Space Agency, Sentinel-2 Spectral Response Functions, 2018, Sentinel-2 document library, accessed October 19, 2020, at https://earth.esa.int/web/sentinel/userguides/sentinel-2-msi/document-library/-/asset_publisher/ Wk0TKajiISaR/content/sentinel-2a-spectral-responses.

Guo, X., Zhang, C., and Wilmshurst, J., 2005, Monitoring grassland health with remote sensing approaches, in Noble, B.F., Martz, D.J.F., and Aitken, A.E., eds., Prairie Perspectives - Geographical Essays: University of Saskatchewan Department of Geography, p. 11-22.

Hauber, D.P., Saltonstall, K., White, D.A., and Hood, C.S., 2011, Genetic variation in the common reed, Phragmites australis, in the Mississippi River Delta marshes-Evidence for multiple introductions: Estuaries and Coasts, v. 34, no. 4, p. 851-862. [Also available at https://doi.org/10.1007/ s12237-011-9391-9.]

Katarzyna, D.-Z., Golinski, P., Jorgensen, M., Molmann, J., Taft, G., Tomaszewska, M., Golinska, B., Budzynska, M., and Gatkowska, M., 2015, Proceedings of 23rd International Grassland Congress 2015-Keynote lectures: p. 30-40. 
Knight, I.A., Wilson, B.E., Gill, M., Aviles, L., Cronin, J.T., Nyman, J.A., Schneider, S.A., and Diaz, R., 2018, Invasion of Nipponaclerda biwakoensis (Hemiptera-Aclerdidae) and Phragmites australis die-back in southern Louisiana, USA: Biological Invasions, v. 20, no. 10, p. 2739-2744. [Also available at https://doi.org/10.1007/s10530018-1749-5.]

Lambertini, C., Mendelssohn, I.A., Gustafsson, M.H.G., Olesen, B., Riis, T., Sorrell, B.K., and Brix, H., 2012, Tracing the origin of Gulf Coast Phragmites (Poaceae) - A story of long-distance disperal and hybridization: American Journal of Botany, v. 99, no. 3, p. 538-551. [Also available at https://doi.org/10.3732/ajb.1100396.]

Liu, Z.-Y., Huang, J.-F., Wu, X.-H., and Dong, Y.-P., 2007, and : Journal of Integrative Plant Biology, v. 49, no. 3, p. 299-306. [Also available at https://doi.org/10.1111/ j.1744-7909.2007.00401.x.]

Qi, J., Chehbouni, A., Huete, A.R., Kerr, Y.H., and Sorooshian, S., 1994, A modified soil adjusted vegetation index: Remote Sensing of Environment, v. 48, no. 2, p. 119-126. [Also available at https://doi.org/10.1016/0034-4257(94)90134-1.]

Ramsey, E., III, and Jensen, J., 1995, Modeling mangrove canopy reflectance using a light interaction model and an optimization technique, in Lyon, J., and McCarthy, J., eds., Wetland and environmental applications of GIS: Boca Raton, Fla., CRC Press, Inc., p. 61-81.

Ramsey, E.W., III, and Rangoonwala, A., 2017, Mapping the change of Phragmites australis live biomass in the lower Mississippi River Delta marshes: U.S. Geological Survey Open-File Report 2017-1098, accessed October 12, 2020, at https://pubs.er.usgs.gov/publication/ofr20171098.

Ramsey, E., III, Rangoonwala, A., and Bannister, T., 2013, Coastal flood inundation monitoring with satellite C-band and L-band synthetic aperture radar data: Journal of the American Water Resources Association, v. 49, no. 6, p. 1239-1260. [Also available at https://doi.org/10.1111/ jawr.12082.]

Ramsey, E., III, Rangoonwala, A., Jones, C.E., and Bannister, T., 2015, Marsh canopy leaf area and orientation calculated for improved marsh structure mapping: Photogrammetric Engineering \& Remote Sensing, v. 81, no. 10, p. 807-816, accessed October 12, 2020, at https://doi.org/10.14358/ PERS.81.10.807.

Rangoonwala, A., and Ramsey, E.W., III, 2019, Monitoring live vegetation in semiarid and arid rangeland environments with satellite remote sensing in northern Kenya: U.S. Geological Survey Open-File Report 2019-1037, 83 p., accessed October 12, 2020, at https://doi.org/10.3133/ ofr20191037.
Rangoonwala, A., and Ramsey, E.W., III, 2020, Phragmites australis live fractional cover yearly map from 2009 to 2019 of the lower Mississippi River Delta using Landsat and Sentinel-2 satellite data: U.S. Geological Survey data release, https://doi.org/10.5066/P9ASPB4E.

Röder, A., Udelhoven, T., Hill, J., del Barrio, G., and Tsiourlis, G., 2008, Trend analysis of Landsat-TM and -ETM+ imagery to monitor grazing impact in a rangeland ecosystem in Northern Greece: Remote Sensing of Environment, v. 112, no. 6, p. 2863-2875. [Also available at https://doi.org/ 10.1016/j.rse.2008.01.018.]

Rundquist, D., Gitelson, A., Leavitt, B., Zygielbaum, A., Perk, R., and Keydan, G., 2014, Elements of an Integrated Phenotyping System for Monitoring Crop Status at Canopy Level: Agronomy (Basel), v. 4, no. 1, p. 108-123, accessed October 12, 2020, at https://doi.org/10.3390/ agronomy 4010108 .

Saltz, D., Schmidt, H., Rowen, M., Karnieli, A., Ward, D., and Schmidt, I., 1999, Grazing impacts by remote sensing in hyper-arid environments: Journal of Range Management, v. 52, no. 5, p. 500-507. [Also available at https://doi.org/ 10.2307/4003778.]

Schneider, S.A., 2019, A key to the flat grass scale genus Nipponaclerda (Hemiptera, Coccomorpha, Aclerdidae): ZooKeys, v. 862, p. 81-87, accessed October 12, 2020, at https://doi.org/10.3897/zookeys.862.35294.

Tucker, C.J., 1979, Red and photographic infrared linear combinations for monitoring vegetation: Remote Sensing of Environment, v. 8, no. 2, p. 127-150. [Also available at https://doi.org/10.1016/0034-4257(79)90013-0.]

U.S. Department of the Interior, Fish and Wildlife Service, 2008, Delta and Breton National Wildlife Refuges, St. Bernard and Plaquemines Parishes, Louisiana: Comprehensive Conservation Plan, 140 p., accessed October 27, 2020, at https://www.fws.gov/southeast/ planning/PDFdocuments/Delta\%20Breton\%20Final/ DeltaBretonFinalCCPdoc.pdf.

Yang, J., Weisberg, P.J., and Bristow, N.A., 2012, Landsat remote sensing approaches for monitoring long-term tree cover dynamics in semi-arid woodlands - Comparison of vegetation indices and spectral mixture analysis: Remote Sensing of Environment, v. 119, p. 62-71. [Also available at https://doi.org/10.1016/j.rse.2011.12.004.] 
For more information about this publication, contact Director, Wetland and Aquatic Research Center U.S. Geological Survey

700 Cajundome Blvd.

Lafayette, Louisiana 70506

For additional information, visit https://www.usgs.gov/centers/wetland-and-aquaticresearch-center-warc

Publishing support provided by Lafayette Publishing Service Center 


\section{罗}

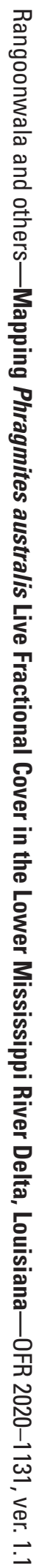

